Article

\title{
Preparation and Characterization of Fenofibrate Microparticles with Surface-Active Additives: Application of a Supercritical Fluid-Assisted Spray-Drying Process
}

\author{
Jeong-Soo Kim ${ }^{1,+}{ }^{\text {, Heejun Park }}{ }^{2,+}$, Eun-Sol Ha ${ }^{3,+}$, Kyu-Tae Kang ${ }^{2}$, Min-Soo Kim ${ }^{3, *}$ and Sung-Joo Hwang ${ }^{4, *}$ (i) \\ 1 Dong-A ST Co., Ltd., Giheung-gu, Yongin 446-905, Korea; js_kim@donga.co.kr \\ 2 College of Pharmacy, Duksung Women's University, 33, Samyangro 144-gil, Dobong-gu, Seoul 01369, Korea; \\ heejunpark@duksung.ac.kr (H.P.); ktkang@duksung.ac.kr (K.-T.K.) \\ 3 College of Pharmacy, Pusan National University, 63 Busandaehak-ro, Geumjeong-gu, Busan 46241, Korea; \\ edel@pusan.ac.kr \\ 4 Yonsei Institute of Pharmaceutical Sciences, College of Pharmacy, Yonsei University, 85 Songdogwahak-ro, \\ Yeonsu-gu, Incheon 21983, Korea \\ * Correspondence: minsookim@pusan.ac.kr (M.-S.K.); sjh11@yonsei.ac.kr (S.-J.H.); \\ Tel.: +82-51-510-2813 (M.-S.K.) \\ + These authors contributed equally to this manuscript.
}

check for

updates

Citation: Kim, J.-S.; Park, H.; Ha, E.-S.; Kang, K.-T.; Kim, M.-S.; Hwang, S.-J. Preparation and Characterization of Fenofibrate Microparticles with Surface-Active Additives: Application of a Supercritical Fluid-Assisted Spray-Drying Process. Pharmaceutics 2021, 13, 2061. https:// doi.org/10.3390/pharmaceutics13122061

Academic Editor: Holger Grohganz

Received: 28 October 2021

Accepted: 26 November 2021

Published: 2 December 2021

Publisher's Note: MDPI stays neutral with regard to jurisdictional claims in published maps and institutional affiliations.

Copyright: (C) 2021 by the authors. Licensee MDPI, Basel, Switzerland. This article is an open access article distributed under the terms and conditions of the Creative Commons Attribution (CC BY) license (https:/ / creativecommons.org/licenses/by/ $4.0 /)$.
Abstract: In this study, supercritical fluid-assisted spray-drying (SA-SD) was applied to achieve the micronization of fenofibrate particles possessing surface-active additives, such as d- $\alpha$-tocopheryl polyethylene glycol 1000 succinate (TPGS), sucrose mono palmitate (Sucroester 15), and polyoxyethylene 52 stearate (Myrj 52), to improve the pharmacokinetic and pharmacodynamic properties of fenofibrate. For comparison, the same formulation was prepared using a spray-drying (SD) process, and then both methods were compared. The SA-SD process resulted in a significantly smaller mean particle size (approximately $2 \mu \mathrm{m}$ ) compared to that of unprocessed fenofibrate (approximately $20 \mu \mathrm{m}$ ) and SD-processed particles (approximately $40 \mu \mathrm{m}$ ). There was no significant difference in the effect on the particle size reduction among the selected surface-active additives. The microcomposite particles prepared with surface-active additives using SA-SD exhibited remarkable enhancement in their dissolution rate due to the synergistic effect of comparably moderate wettability improvement and significant particle size reduction. In contrast, the SD samples with the surface-active additives exhibited a decrease in dissolution rate compared to that of the unprocessed fenofibrate due to the absence of particle size reduction, although wettability was greatly improved. The results of zeta potential and XPS analyses indicated that the surface-active additive coverage on the surface layer of the SD-processed particles with a better wettability was higher than that of the SA-SDprocessed composite particles. Additionally, after rapid depletion of hydrophilic additives that were excessively distributed on the surfaces of SD-processed particles, the creation of a surface layer rich in poorly water-soluble fenofibrate resulted in a decrease in the dissolution rate. In contrast, the surface-active molecules were dispersed homogeneously throughout the particle matrix in the SA-SD-processed microparticles. Furthermore, improved pharmacokinetic and pharmacodynamic characteristics were observed for the SA-SD-processed fenofibrate microparticles compared to those for the SD-processed fenofibrate particles. Therefore, the SA-SD process incorporating surface-active additives can efficiently micronize poorly water-soluble drugs and optimize their physicochemical and biopharmaceutical characteristics.

Keywords: supercritical fluid assisted spray-drying (SA-SD); fenofibrate; surface-active additive; spray-drying (SD); microparticle; biopharmaceutical performance

\section{Introduction}

Biopharmaceutics Classification System (BCS) class II drugs must overcome challenges during the pharmaceutical development process that include determining a means to 
enable sufficient bioavailability due to their low solubility. Drugs that exhibit poor aqueous solubility do not dissolve rapidly and, thus, may not be adequately absorbed through the oral route of administration. Therefore, major efforts have been made in the pharmaceutical industry to improve the bioavailability and/or the onset of action of these drugs by focusing on increasing the dissolution rate of poorly water-soluble drugs via the reduction of particle size (i.e., micronization) through the use of hydrophilic surface-active materials [1-8]. In response to these needs, microparticle preparation technologies using supercritical fluids (SCF), particularly carbon dioxide, have been applied to improve the physicochemical properties of drug particles via fine control of particle precipitation. The advantages of particle formation processes using supercritical carbon dioxide $\left(\mathrm{SC}-\mathrm{CO}_{2}\right)$ include rapid and efficient mass transfer and higher solvent power compared to these characteristics using conventional solvents $[9,10]$. Additionally, these SCF properties can be finely adjusted by varying several process parameters, such as pressure and temperature. In general, particle formation techniques using $\mathrm{SC}-\mathrm{CO}_{2}$ are classified into four groups based on the solvating behavior of SCF, including (i) rapid expansion of supercritical solution (RESS) process using SCF as a solvent [11-21], (ii) supercritical anti-solvent (SAS) processes using SCF as an antisolvent [22-26], (iii) particles from a gas saturated solution (PGSS) process using as a solute [27-31], and (iv) several processes using SCF as an atomizing agent, such as carbon dioxide-assisted nebulization with a bubble fryer ${ }^{\circledR}$ (CAN-BD) [32], supercritical fluid-assisted atomization (SAA) [33], and supercritical fluid-assisted spraydrying (SASD) $[34,35]$. These SCF technologies have been introduced as promising particle engineering techniques for the control of particle size from micro- to nano-meter dimensions with a narrow particle size distribution (PSD) [36-48].

In particular, several processes incorporating the use of SCF have recently been used to allow atomizing agents to nebulize organic solutions containing substrates, and these have received much attention. These processes permit the treatment of any compound regardless of the compound's solubility in $\mathrm{SC}-\mathrm{CO}_{2}$. The substrate is dissolved into an organic or an aqueous solution, which is mixed under pressure with the SCF, forming a mixed fluid. Then, the mixed fluid flows through a restrictor and is rapidly expanded through the suitable device to form an aerosol. The aerosol droplets are dried to form fine particles [49-51]. These processes provide very efficient and versatile methods for particle formation in the context of drug delivery systems. It is clear that the SAA and CAN-BD processes overcome a number of the drawbacks that are inherent to conventional processes that use SCF. Unfortunately, several problems, such as the recovery of produced nanoparticles, the requirement of high temperatures for evaporating liquid solvents, and complications related to the application of practical drug production related to GMP compliance, still exist.

Based on the principle regarding SAA and CAN-BD processes, a group led by Hwang developed a novel SA-SD process as a valid alternative to the conventional SD process and the SAS process for the preparation of nanoparticles [34,35]. In the SA-SD process, $\mathrm{SC}-\mathrm{CO}_{2}$ acts both as a co-solvent that is miscible with the drug solution to be treated and as an atomizing agent that can atomize the drug solution in a fine droplet. Moreover, organic and inorganic solvents can be used for fine particle formation of both hydrophilic and hydrophobic drugs [49,51-57].

In the present study, fenofibrate was chosen as the model compound due to its practical insolubility in water. The SA-SD process was applied to achieve the micronization of fenofibrate particles possessing several surface-active additives, such as $\alpha$-tocopheryl polyethelyene glycol 1000 succinate (TPGS), sucrose monopalmitate (Sucroester 15), and polyoxyethylene 40 stearate (Myrj 52), to enhance the wettability and dissolution rate and, thus, improve the pharmacokinetic (PK) and pharmacodynamic (PD) effects of fenofibrate. Among the various SA-SD process parameters, critical factors, such as concentration of drug solution, $\mathrm{CO}_{2}$ injection rate, and contents of surface-active additives [51], that can show a dramatic effect on the performance of the SA-SD processed particles were evaluated through experimental design using a three-factor, three-level Box-Behnken 
design (BBD) with three replicates at the center point to build response surface models, and the optimized process parameters and the optimized formula were, thus, determined. Finally, the SA-SD process was compared to the spray-drying (SD) process in terms of the physicochemical and biological performance of the composite particles produced by two different processes. Physicochemical characterizations, including particle size analysis, contact angle measurement, zeta potential measurement, SEM, DSC, PXRD, FT-IR, contact angle measurement, and dissolution tests, were also performed to evaluate the effect of the addition of hydrophilic additives on the in vitro performance and morphology of the SA-SD-processed fenofibrate particles. Additionally, the effect of the dissolution rate enhancement on the pharmacokinetic and pharmacodynamic performance of fenofibrate was studied in Sprague-Dawley rats.

\section{Materials and Methods}

\subsection{Materials}

Fenofibrate (MW 360.84) and Myrj 52 (MW 2046.58) were supplied from Sigma (St. Louis, MO, USA). TPGS (MW 1513) was obtained from Eastman Chemical Co. (Kingsport, TN, USA). Sucroester 15 (MW 580.71) was kindly supplied by Gattefossè (Saint-Priest, France). The chemical structures of fenofibrate and additives used are presented in Figure S1 (Supplementary Material). Carbon dioxide $\left(\mathrm{CO}_{2}\right.$, purity $\left.99.9 \%\right)$ was supplied from Hanmi Gas Co., Ltd. (Daejeon, Korea). Sodium lauryl sulfate (extra-pure grade) was obtained from Duksan Pure Chemicals (Ansan, Korea). Ethanol (purity 99.85\%) was supplied from Hayman Ltd. (Essex, UK). All other solvents were of HPLC grade.

\subsection{Preparation of Fenofibrate Microparticles \\ 2.2.1. SA-SD Process}

Figure 1a,b, respectively, depict the SA-SD apparatus and its atomization mechanism that was used to perform all the experiments in this study. The SA-SD apparatus consists of four feed lines used to deliver $\mathrm{CO}_{2}$, the drug solution, atomizing air, drying air, and two process vessels, including a mixing chamber (approximate internal volume $30 \mathrm{~cm}^{3}$ ) and a precipitator (approximate internal volume $6000 \mathrm{~cm}^{3}$ ). Liquid $\mathrm{CO}_{2}$ and the drug/additive solution were introduced at constant feed rates into the mixing chamber using two high pressure pumps that included a Suflux ${ }^{\circledR}$ plunger type metering pump (Ilshin Autoclave Co., Daejeon, Korea) and a high-pressure liquid pump (model 307, Gilson, Middleton, WI, USA) for $\mathrm{CO}_{2}$ and the drug/additive solution, respectively. The mixing chamber is a high-pressure vessel loaded with glass beads (diameter $1.5 \mathrm{~mm}$ ) for vigorous mixing of $\mathrm{CO}_{2}$ and the drug solution. The mixture of $\mathrm{CO}_{2}$ and the drug/additive solution was transported from the mixing chamber to the coaxial nozzle and then sprayed into the precipitator with heated air for rapid mass transfer. In the precipitator, an additional heated air flow was also delivered for rapid evaporation of ethanol that was used as a solvent. The pressure of the precipitator was maintained close to atmospheric conditions using an aspiration pump (aspiration flow $400 \mathrm{~L} / \mathrm{min}$, Woosung Vacuum, Jeju, Korea) during the particle formation process. All particle formation processes were performed at the optimal pressure and temperature to achieve complete miscibility of $\mathrm{CO}_{2}+$ ethanol + fenofibrate + additive by adjusting the valve located in the coaxial nozzle. After the particle formation process, the precipitated fenofibrate microparticles were collected from the baffle dust collector that was designed to allow the gas stream to make a sudden change of direction and from the wire mesh filter located at the bottom of the precipitator. 


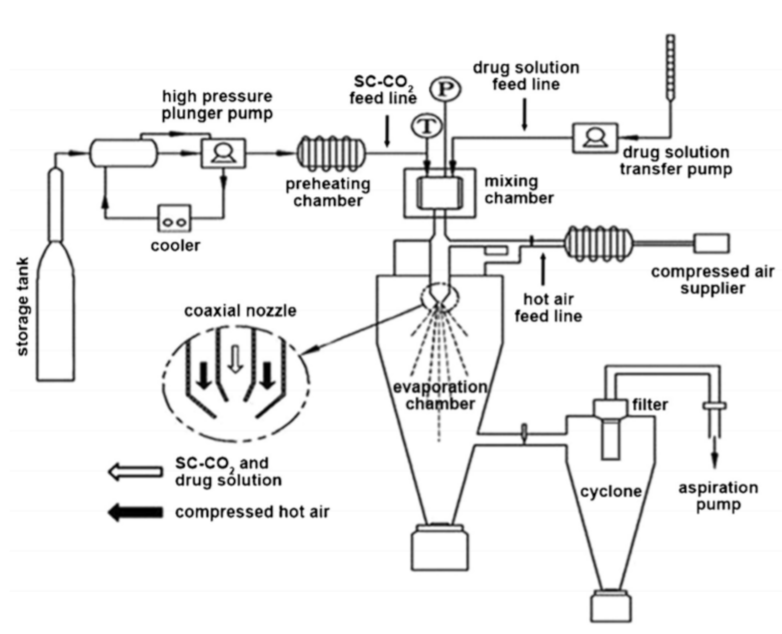

(a)

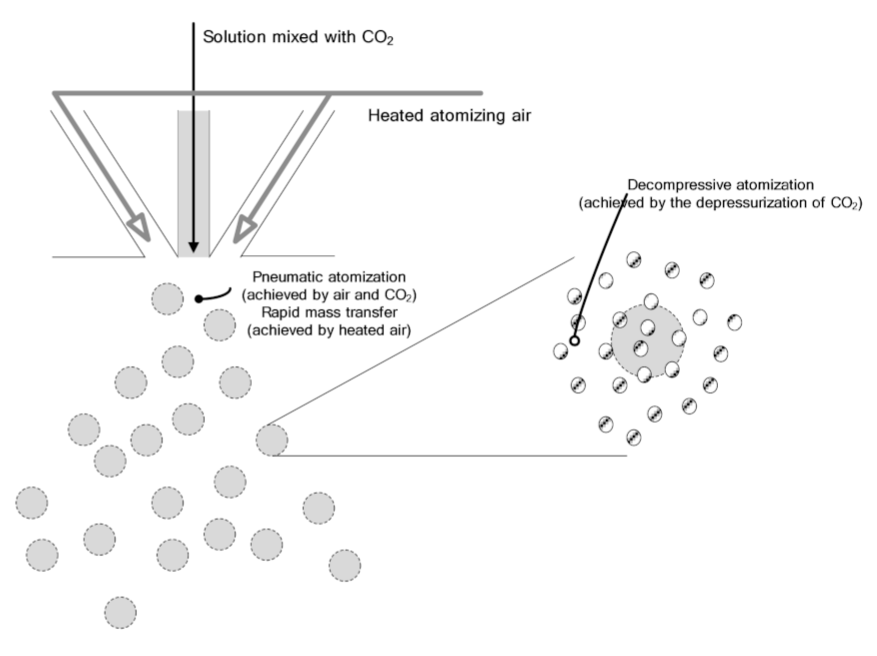

(b)

Figure 1. Schematic diagram of (a) the apparatus (reprinted from Reference [25] with permission, Elsevier 2015) and (b) the atomization mechanism the SA-SD process.

\subsubsection{Box-Behnken Design (BBD)}

Response surface methodology was combined with Box-Behnken design (BBD) to determine the effect of the additives on the SA-SD process performance and the twofactor interaction between the $\mathrm{CO}_{2}$ injection rate and drug solution concentration, and this approach was also used to investigate the effect of the additives on the SA-SD processed particles. A three-factor and three-level BBD with three replicates of the center point was selected to generate the response surface models. The three factors included the drug/additive solution concentration (X1), the $\mathrm{CO}_{2}$ injection rate $(\mathrm{X} 2)$, and the content of additive (X3), and the responses were the mean particle size, the SPAN value, and the dissolution efficiency of fenofibrate at $30 \mathrm{~min}\left(\mathrm{DE}_{30}\right)$. The DE calculation method is mentioned in below Section 2.3.8. The experimental runs with independent variables, including the drug/additive solution concentration, $\mathrm{CO}_{2}$ injection rate, and additive content, are presented in Tables S1-S3 (Supplementary Material) for Sucroester 15, TPGS, and Myrj 52, respectively. The design was constructed using Design-Expert software (version 7.0, Stat-Ease, Inc., Minneapolis, MN, USA).

\subsubsection{Preparation of Fenofibrate Microcomposite Particles under Optimized Conditions}

Briefly, solutions of fenofibrate/Sucroester 15, fenofibrate/TPGS, and fenofibrate/Myrj 52 in ethanol were prepared. Then, a fenofibrate/additive solution $(20 \mathrm{mg} / \mathrm{mL})$ and supercritical $\mathrm{CO}_{2}$ were co-injected into the mixing chamber that was filled with supercritical $\mathrm{CO}_{2}$ $\left(12 \mathrm{MPa}, 40{ }^{\circ} \mathrm{C}\right.$ ) at $10 \mathrm{~mL} / \mathrm{min}$ and $35 \mathrm{~g} / \mathrm{min}$, respectively. Other process conditions were as follows: drying air inlet temperature, $65^{\circ} \mathrm{C}$; outlet temperature, $35 \sim 40{ }^{\circ} \mathrm{C}$; atomization air pressure, $0.3 \mathrm{MPa}$; aspiration velocity, $0.40 \mathrm{~m}^{3} / \mathrm{min}$. During the SA-SD process, the pressure of the mixing chamber was constantly controlled using a needle valve located on the coaxial nozzle. After the particle formation process, fenofibrate composite particles were collected from the baffle dust collector that was designed to allow the gas stream to make a sudden change in direction and from the wire mesh filter that was located at the bottom of the precipitator. The formulations of the SA-SD-processed fenofibrate microparticles with surface-active excipients are summarized in Table 1. 
Table 1. The formulations of the fenofibrate microparticles with surface-active additives.

\begin{tabular}{cccc}
\hline Formula & $\begin{array}{c}\text { Surface-Active } \\
\text { Additive }\end{array}$ & $\begin{array}{c}\text { Content }(w / w, \%) \text { of } \\
\text { Additive in Solid Formula }\end{array}$ & $\begin{array}{c}\text { Particle Formation } \\
\text { Process }\end{array}$ \\
\hline SS1 & Sucroester 15 & 5 & $\begin{array}{c}\text { Supercritical assisted } \\
\text { spray-drying (SA-SD) }\end{array}$ \\
SS2 & TPGS & 5 & SA-SD \\
SS3 & Myrj 52 & 5 & SA-SD \\
SD1 & Sucroester 15 & 5 & Spray-drying (SD) \\
SD2 & TPGS & 5 & SD \\
SD3 & Myrj 52 & 5 & SD \\
\hline
\end{tabular}

\subsubsection{Conventional Spray-Drying (SD) Process}

Fenofibrate and each additive were dissolved in ethanol to obtain a clear solution. The spray drying process was performed using the SA-SD apparatus without $\mathrm{CO}_{2}$ flow at conditions that included: $20 \mathrm{mg} / \mathrm{mL}$ of drug solution concentration; $65^{\circ} \mathrm{C}$ drying air inlet temperature; $35 \sim 40{ }^{\circ} \mathrm{C}$ outlet temperature; $10 \mathrm{~mL} / \mathrm{min}$ for drug solution feeding speed; $0.3 \mathrm{MPa}$ atomization air pressure; $0.40 \mathrm{~m}^{3} / \mathrm{min}$ aspiration velocity. The formulations of the spray-dried fenofibrate microparticles are presented in Table 1.

\subsection{Physicochemical Characterization of Fenofibrate Microparticles \\ 2.3.1. Particle Size Analysis}

The analysis examining prepared particle size was conducted using a Microtrac ${ }^{\circledR}$ X-100 (Honeywell, Montgomeryville, PA, USA) based on the laser diffraction method. The Microtrac ${ }^{\circledR}$ X-100 system possesses a detection range of $0.021-704 \mu \mathrm{m}$. Fenofibrate particles were dispersed in distilled water and sonicated prior to measurement to achieve complete dispersion.

\subsubsection{Powder X-ray Diffraction (PXRD)}

The powder X-ray diffraction patterns of the samples were obtained using a Rigaku D/Max-2200 Ultima/PC powder X-ray diffraction system (Rigaku, Tokyo, Japan) with $\mathrm{Ni}$-filtered $\mathrm{Cu}-\mathrm{K} \alpha$ radiation. The $2 \theta$ scan range was $4-60^{\circ}$ with a step size of $0.02^{\circ}$ and a scan speed of $4^{\circ} \min ^{-1}$.

\subsubsection{Differential Scanning Calorimetry (DSC)}

Samples in the range of $2-5 \mathrm{mg}$ of fenofibrate particles were added to crimp-sealed aluminum pans and measured on a Sinco S-650 DSC (Sinco, Seoul, Korea). The samples were heated at a rate of $5{ }^{\circ} \mathrm{C} / \mathrm{min}$ from $30^{\circ} \mathrm{C}$ to $100^{\circ} \mathrm{C}$. The samples were purged with nitrogen gas at $20 \mathrm{~mL} / \mathrm{min}$. The DSC was calibrated using an indium standard.

\subsubsection{Scanning Electron Microscopy (SEM)}

SEM images of fenofibrate microparticles were obtained using a field-emission scanning electron microscope (JSM-7000F, JEOL Ltd., Tokyo, Japan). Fenofibrate particles were placed on aluminum stubs using double-adhesive carbon tape. Then, the particles were coated with fold/palladium using a FineCoat Sputter (JFC-1100, Jeol, Ltd., software (Akishima, Tokyo, Japan)).

\subsubsection{X-ray Photoelectron Spectroscopy (XPS)}

XPS analysis was performed using a Thermo Multilab 2000 photoelectron spectrometer (Thermo Fisher Scientific, Waltham, MA, USA) to analyze the solid surfaces of SA-SDprocessed fenofibrate microcomposite particles with surface-active additives [58]. The electrons emitted from the sample originate from the near-surface region of most solids (analysis depth: $10 \mathrm{~nm}$ ). To avoid further scattering, the analysis must be performed in an ultra-high vacuum of $10^{-8}$ Torr. An $\mathrm{Al} \mathrm{K \alpha}$ X-ray source was used in this instrument. The applied take-off angle of the photoelectrons for detection was perpendicular to the 
sample holder. For the analysis, it was assumed that all components existed in patches, that the patches were thicker than the analysis depth, and that the data for the atomic surface composition were converted into molecular surface composition based on the assumption that the surface composition is a linear combination of the different molecular species. The area analyzed consisted of a region $<1 \mathrm{~mm}^{2}$, and three measurements were repeated three times for each sample.

\subsubsection{Zeta Potential Measurement}

The zeta potential of SA-SD-processed fenofibrate particles was measured using an electrophoretic light scattering spectrophotometer (ELS-8000, Otsuka Electronics Co., Osaka, Japan). The powder samples were homogeneously dispersed in water and used for zeta potential analysis.

\subsubsection{Contact Angle Measurement}

The contact angle measurements for the SA-SD-processed composite particles were performed using a Phoenix 300 contact angle analyzer (Surface Electro-Optics, Seoul, Korea) with a capture interval of $20 \mathrm{~ms}$. The distilled water contained in a syringe impacted the pellets, and this followed by image capture and analysis. To form a pellet, an appropriate amount of solid sample was weighed and compacted using a Perkin Elmer hydraulic press (ATSFAAR, PerkinElmer, Inc., Waltham, MA, USA) at $5 \mathrm{t}$ force for $10 \mathrm{~s}$. As the contact angle decreased with time due to the spreading and absorption phenomena, the equilibrium contact angle was determined by extrapolating the fitted linear function at $t=0$ [59]. The equilibrium contact angle measurements were performed at c to guarantee reproducibility.

\subsubsection{Dissolution Test}

Dissolution tests of fenofibrate particles (equivalent to $160 \mathrm{mg}$ as fenofibrate) were performed according to the USP XXVIII Type II (paddle method) using a VK7000 dissolution apparatus (VK7000, Vankel, Edison, NJ, USA). The speed of paddle rotation was $75 \mathrm{rpm}$, and $1000 \mathrm{~mL}$ of aqueous solution containing $0.025 \mathrm{M}$ sodium lauryl sulfate was used as the dissolution medium. Samples $(2 \mathrm{~mL})$ were collected at predetermined sampling time points and then filtered using a $0.45 \mu \mathrm{m}$ PTFE syringe filter. The concentration of the dissolved drug was measured by HPLC analysis. The HPLC system consisted of a pump (LC-10AD, Shimadzu, Kyoto, Japan) and a UV detector (SPD-10A, Shimadzu, Kyoto, Japan). The column used was Lichrospher ${ }^{\circledR} \mathrm{RP} 18(4.6 \times 50 \mathrm{~mm}, 5 \mu \mathrm{m}$, Merck, Darmstadt, Germany). The composition of the mobile phase was a mixture of water and acetonitrile (30:70) at $\mathrm{pH} 2.5$. The flow rate and UV-detection wavelength condition were $1.2 \mathrm{~mL} / \mathrm{min}$ and $286 \mathrm{~nm}$, respectively. This HPLC analysis method was adopted from the assay method of fenofibrate tablet monograph in the United States Pharmacopeia/National Formulary (USP/NF) [60,61]. Dissolution efficiency $\left(\mathrm{DE}_{t}\right)$ was calculated from the area under the dissolution curve at time $t$ (measured using the trapezoidal rule) and expressed as the percentage of the area of the rectangle described by $100 \%$ dissolution at the same time [62]. All tests were performed in triplicate.

\subsection{In Vivo Studies Using Sprague-Dawley Rats}

Animal experiments were performed according to the guidelines for the care and use of laboratory animals. The animal experimental protocols (Approval Code: I-1708186) were approved by the Institutional Review Board of the nonclinical contract research organization KPC laboratory (approval date: 29 August 2017).

\subsubsection{Pharmacokinetic (PK) Study}

Male Sprague-Dawley rats (6-7 weeks old, 180-200 g) were obtained from Samtaco Bio Korea, Inc. (Osan, Korea). The rats were housed in a cage and maintained on a 12-h light/dark cycle at room temperature $\left(25^{\circ} \mathrm{C}\right)$ and a relative humidity of $55 \pm 10 \%$. General and environmental conditions were strictly monitored. All rats were permitted free access 
to tap water and a pelleted diet during maintenance; however, they were deprived of food for $24 \mathrm{~h}$ prior to drug administration. Food intake was permitted again at $4 \mathrm{~h}$ after dosing. The rats were divided into seven groups consisting of seven animals each. SD-and SA-SD-processed powder samples were freshly prepared and used for animal studies. One milliliter of suspensions containing fenofibrate powder samples (equivalent to $50 \mathrm{mg} / \mathrm{kg}$ body weight as fenofibrate) in water with $0.2 \% w / v$ methylcellulose was administered to each group via oral administration using oral zonde. Blood samples were collected from the tail vein at predetermined time points that included pre-dose and 20, 40, 60, 90, 120, $180,240,360,480$, and $720 \mathrm{~min}$ post-dosing. The collected blood samples were stored in an ice bath at approximately $4^{\circ} \mathrm{C}$ and then centrifuged at $4{ }^{\circ} \mathrm{C}$ and $10,000 \mathrm{rpm}$ for $10 \mathrm{~min}$. After centrifugation, serum was collected and stored in individual plastic tubes at $-20{ }^{\circ} \mathrm{C}$ until analysis.

For the preparation of the HPLC analysis sample solution, $200 \mu \mathrm{L}$ of each serum sample was transferred into a plastic tube and then spiked with $20 \mu \mathrm{L}$ of internal standard solution (clofibric acid, $2000 \mu \mathrm{g} / \mathrm{mL}$ ), and this was followed by the addition of $200 \mu \mathrm{L} 1 \mathrm{M}$ $\mathrm{HCl}$. The mixture was mixed for $30 \mathrm{~s}$ using a vortexer, and $1 \mathrm{~mL}$ of $\mathrm{n}$-hexane/ethyl acetate $(9: 1 \mathrm{v} / \mathrm{v})$ mixture solution was then added and mixed for $5 \mathrm{~min}$. After centrifugation at $13,000 \mathrm{rpm}$ for $10 \mathrm{~min}$, the collected clear supernatants were transferred to a tube and then heated (at $40^{\circ} \mathrm{C}$ ) to evaporate for drying under a nitrogen flow. After complete evaporation, the residue was reconstituted in $1 \mathrm{~mL}$ of solvent (distilled water/acetonitrile $=7: 3$ ). To obtain the supernatant, the samples were centrifuged at $3000 \mathrm{rpm}$ for $5 \mathrm{~min}$. The clear $50 \mu \mathrm{L}$ aliquot collected from the supernatant was injected into the HPLC system for the analysis of fenofibric acid that is a metabolite of fenofibrate [63]. The HPLC system (Waters 2690 alliance, Waters, Milford, MA, USA) was equipped with an autosampler and photodiode array UV detector (Waters ${ }^{\text {TM }}$ 996, Waters, Milford, MA, USA). The previously reported HPLC analysis method was used to analyze serum drug concentration [62]. The C-18 reverse phase column was used as the stationary phase (Xterra ${ }^{\mathrm{TM}} \mathrm{RP}-185 \mu \mathrm{m}$, Waters, Milford, MA, USA). The mobile phase ( $\mathrm{pH} 3.4$ ) was composed of a mixture of $0.02 \mathrm{M}$ phosphate buffer solution and acetonitrile $(55: 45, v / v)$. The flow rate of the mobile phase and UV detection wavelength were $1.2 \mathrm{~mL} / \mathrm{min}$ and $286 \mathrm{~nm}$, respectively. Calibration samples were prepared as described above, with the exception that, instead of $200 \mu \mathrm{L}$ of a serum sample, a mixture of stock solution $(20 \mu \mathrm{L})$ and blank rat serum $(180 \mu \mathrm{L})$ were used. Calibration curves were constructed in the range of $0.5-200 \mu \mathrm{g} / \mathrm{mL}$ for fenofibric acid using the ratio of fenofibric acid and IS. The PK parameters, including maximum plasma concentration $\left(C_{\max }\right)$, time point of maximum plasma concentration $\left(T_{\max }\right)$, and area under the curve from $0 \mathrm{~h}$ to $12 \mathrm{~h}\left(\mathrm{AUC}_{0-12}\right)$, were calculated from drug plasma concentration-time curve.

\subsubsection{Pharmacodynamic (PD) Studies in Sprague-Dawley Rats}

The in vivo hypolipidemic efficacy of the SA-SD-processed fenofibrate microparticles was evaluated in comparison to SD-processed fenofibrate microparticles and unprocessed fenofibrate in 6-7 weeks old male Sprague-Dawley rats (Samtaco, Korea). The animals were divided into nine groups of four animals each prior to distribution for the experiment. Hyperlipidemia was induced by intraperitoneal injection of normal saline containing Triton WR 1339 (equivalent to $250 \mathrm{mg} / \mathrm{kg}$ body weight) [64]. Intraperitoneal injection of Triton inhibits peripheral lipoprotein lipase enzymes that are responsible for the removal of lipid particles from the body [65]. The injection of Triton resulted in a temporary increase in serum lipid levels. The control group was intraperitoneally injected with normal saline instead of Triton. After induction of hyperlipidemia, $1 \mathrm{~mL}$ of suspensions containing fenofibrate powder samples (equivalent to $10 \mathrm{mg} / \mathrm{kg}$ body weight as fenofibrate) in water with $0.2 \% w / v$ methylcellulose was administered to each group via oral administration using oral zonde. Distilled water $(1 \mathrm{~mL})$ was administered to the control group instead of the drug sample. Blood samples were collected by retroorbital puncture under light ether anesthesia beginning at $24 \mathrm{~h}$ and $48 \mathrm{~h}$. The collected serum samples were analyzed 
for the measurement of total cholesterol and triglycerides (TG) using an in vitro diagnostic kit (Stanbio Laboratory, Boerne, TX, USA).

\section{Results and Discussion}

\subsection{Optimization of Fenofibrate Microparticle Formation Using Box-Behnken Design (BBD)}

The experimental runs with the independent variables, including the drug/additive solution concentration, $\mathrm{CO}_{2}$ injection rate, and additive content based on the BBD and the pharmaceutical evaluation results of microparticles obtained through each run, are presented in the Supplementary Material. It was demonstrated that the BBD is suitable for the exploration of quadratic response surfaces and the construction of a second-order polynomial model, thus helping to understand the effect of various independent formulation or process variables on the particle formation via the SA-SD process using a small number of experimental runs. As shown in Tables S1-S4 and Figures S2-S7, it is obvious that the particle size and distribution (SPAN value) were significantly affected by drug/additive solution concentration and $\mathrm{CO}_{2}$ injection rate, as well as the results of screening design. The content of additive has no significant effect on the particle size and distribution of the SA-SD processed surface modified microparticles. In addition, no interaction between $\mathrm{drug} /$ additive solution concentration and $\mathrm{CO}_{2}$ injection rate was observed. From these results, it can be suggested that the addition of hydrophilic surfactants could not affect the particle formation process of the SA-SD. In addition, two factor interaction between the drug/additive solution concentration and the content of additive was estimated statistically significant effect.

Through the analysis of the design of the experimental results described in the Supplementary Material, the optimum SA-SD process conditions (solution concentration: $20 \mathrm{mg} / \mathrm{g}, \mathrm{CO}_{2}$ injection rate: $25 \mathrm{~g} / \mathrm{min}$, contents of additives: $5 \%$ ) with a small particle size and narrow size distribution (small SPAN value) (Figures S8-S13), good wettability, and fast dissolution rate (Figures S14-S16) were determined and selected for further study. In summary, the dissolution efficiency after $30 \mathrm{~min}\left(\mathrm{DE}_{30} \mathrm{~min}\right.$ ) was $46.30 \%$ for the unprocessed fenofibrate, while it was $62.50 \%, 60.95 \%$, and $55.19 \%$ for the optimized SA-SD-processed fenofibrate-additive microcomposite particles with Sucroester 15 (S8), TPGS (T8), and Myrj 52 (M8), respectively. A dramatic enhancement of the dissolution rate was observed for the SA-SD-processed fenofibrate microparticles. This means that the particle size reduction has dramatic positive effect on the dissolution rate. In addition, these phenomena may be ascribed to the wettability improvement of the SA-SD-processed composite particles that was achieved by the addition of a hydrophilic surfactant. Among the additives used, Sucroester 15 demonstrated the best performance in regard to the enhancement of the dissolution rate, and this may be due to the relatively good dispersity resulting from the relatively large zeta potential value $(-23.85 \mathrm{mV})$ compared to those of TPGS $(-10.71 \mathrm{mV})$ and Myrj $52(-12.05 \mathrm{mV})$ (Tables S5-S7, Supplementary Material). SA-SD-processed fenofibrate microparticles are expected to improve the biopharmaceutical performance of orally administered fenofibrate.

\subsection{Physicochemical Characterization of Fenofibrate-Additive Microcomposite Particles}

There was no remarkable difference in the DSC thermogram (showing melting temperature and heat of fusion), PXRD pattern, and FT-IR spectrum among all samples, including raw fenofibrate, and this indicates that raw fenofibrate and all prepared fenofibrate microparticles exist as the same polymorph with similar crystallinity. This result also indicates that the SA-SD processes could not alter the conformational structure of fenofibrate crystals or the SD process (Figure 2). 


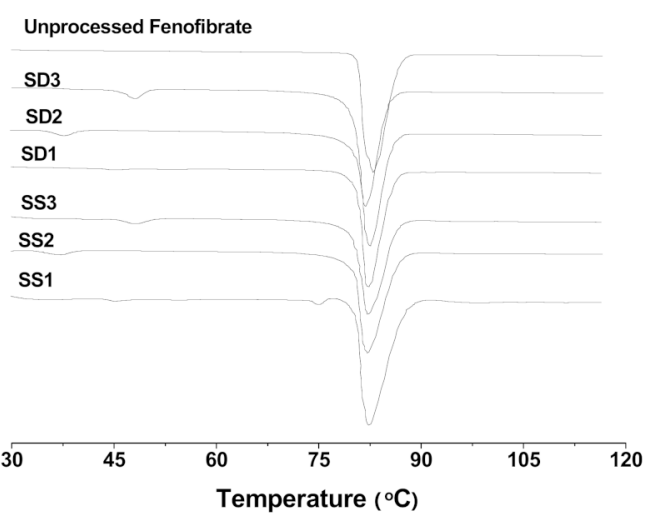

(a)

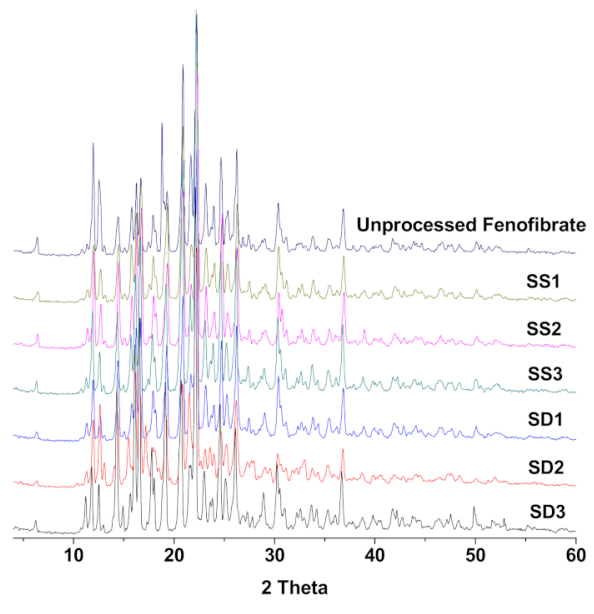

(b)

Figure 2. (a) DSC thermograms and (b) X-ray diffraction patterns of the SA-SD-processed and the SD-processed fenofibrate surface-active additive microcomposite particles.

The SEM images and particle size distributions are presented in Figures 3 and 4, respectively. As indicated by the SEM images, both the SA-SD and SD processes resulted in irregularly shaped crystals, and no differences were observed in the morphologies. However, the degree of particle size reduction was remarkably different between the SASD and SD processes. The SD process produced fenofibrate microparticles possessing mean particle sizes of $33.98 \pm 1.21,43.76 \pm 1.53$, and $49.16 \pm 1.37 \mu \mathrm{m}$ for SD1, SD2, and SD3, respectively, while the SA-SD process produced particles possessing mean particle sizes of $1.86 \pm 0.21,2.17 \pm 0.12$, and $2.04 \pm 0.25 \mu \mathrm{m}$ for SS1, SS2, and SS3, respectively. These results indicate that $\mathrm{CO}_{2}$ was not only acted as a cosolvent and also acted as an atomizing agent for inducing the formation of smaller and finer particles.

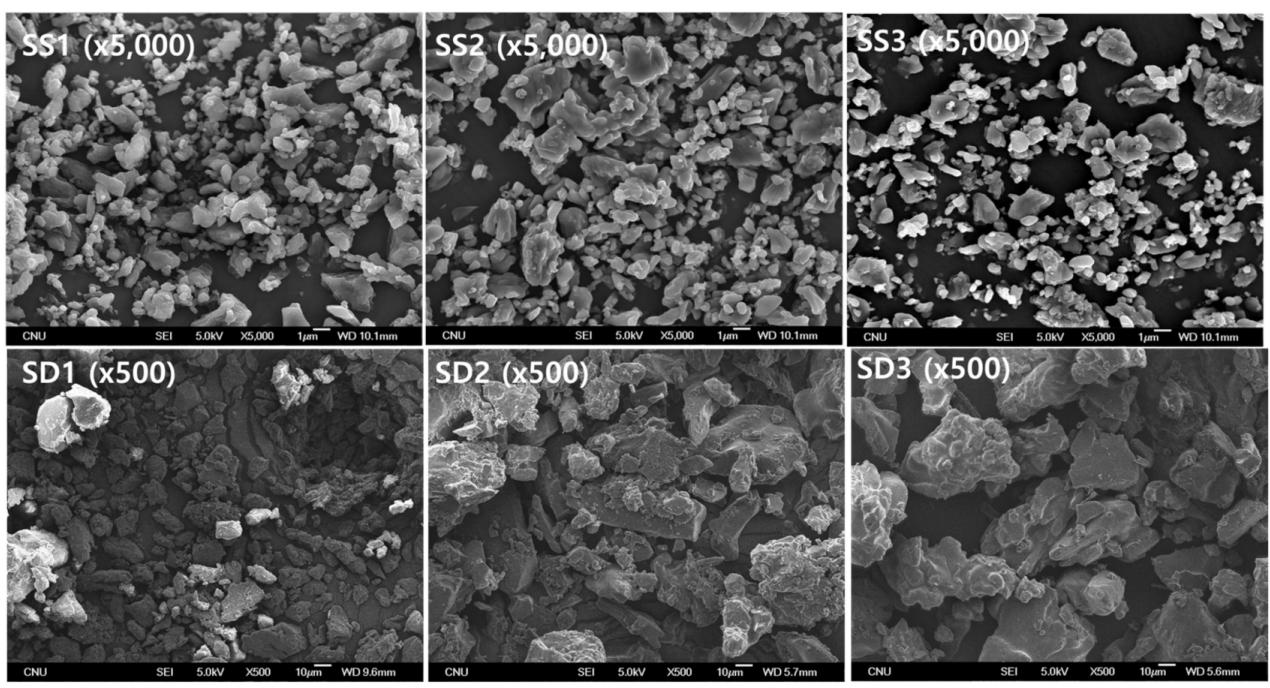

Figure 3. The SEM micrographs obtained by two different particle formation processes, including the SA-SD process (upper) and the SD process (lower).

The results of the particle size analysis, zeta potential evaluation, and contact angle analysis are summarized in Table 2. While zeta potential values for the SA-SD-processed microparticles were $-22.56,-9.87$, and $-11.74 \mathrm{mV}$ (for SS1, SS2, and SS3, respectively), those of the SD-processed particles were $-31.29,-7.42$, and $-6.39 \mathrm{mV}$ for SD1, SD2, and SD3, respectively. At the same content of each additive, the change in zeta potential (absolute value) was increased in the SD process. The equilibrium contact angles for both 
the SA-SD- and SD-processed particles were $57.42^{\circ}, 58.78^{\circ}, 60.01^{\circ}, 41.05^{\circ}, 42.17^{\circ}$, and $28.97^{\circ}$ for SS1, SS2, SS3, SD1, SD2, and SD3, respectively. The fenofibrate microparticles produced by the SD process exhibited a lower contact angle than did the composite particles produced by the SA-SD process. To identify the relationship between the zeta potential value and the contact angle, the zeta potential values of all the prepared particles were plotted with the equilibrium contact angle (Figure 5). Plotting the cosine values of the contact angles versus zeta potential values revealed a general trend of decreasing the contact angles with the zeta potential values moving away from $-17.12 \mathrm{mV}$ (the zeta potential value of unprocessed fenofibrate), despite a significant scatter around this trend. Therefore, the addition of the surfactant increases the wettability of fenofibrate microparticles. The combination of zeta potential measurement and contact angle measurement, thus, provides useful information on the wettability of the drug/additive composite particles.

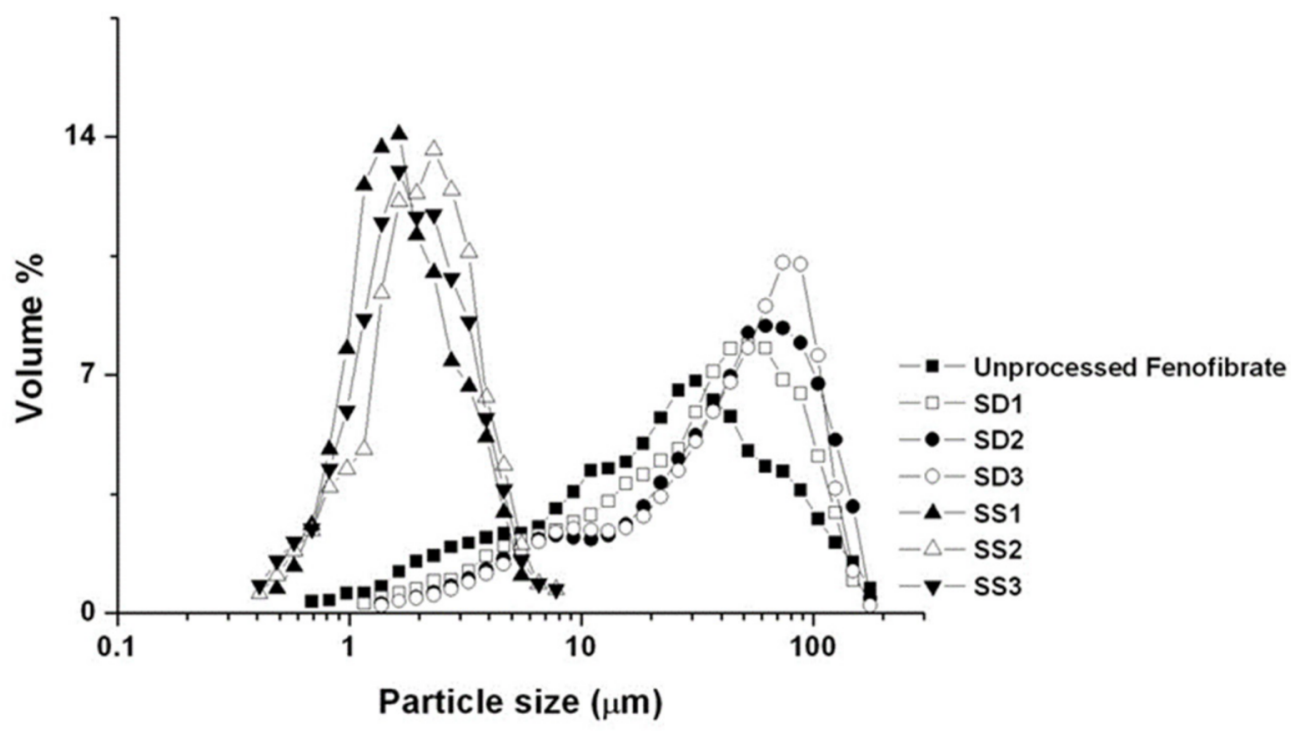

Figure 4. Particle size distribution of the fenofibrate microparticles produced by two different particle formation processes (SD and SA-SD).

Table 2. The results of particle size, zeta potential, and contact angle analyses (mean \pm S.D., $n=3$ ).

\begin{tabular}{cccccccc}
\hline Formula & \multicolumn{2}{c}{$\begin{array}{c}\text { Mean Particle } \\
\text { Size }(\boldsymbol{\mu m})\end{array}$} & SPAN $^{\mathbf{a}}$ & \multicolumn{2}{c}{ Zeta Potential (mV) } & \multicolumn{2}{c}{ Contact Angle $\left(^{\circ}\right.$ ) } \\
\hline Raw ${ }^{\mathrm{b}}$ & 23.80 & \pm 0.64 & 4.25 & -17.12 & \pm 1.13 & 80.38 & \pm 2.83 \\
\hline SS1 & 1.86 & \pm 0.21 & 1.27 & -22.56 & \pm 1.74 & 57.42 & \pm 4.12 \\
SS2 & 2.17 & \pm 0.12 & 1.18 & -9.87 & \pm 1.35 & 58.78 & \pm 3.37 \\
SS3 & 2.04 & \pm 0.25 & 1.22 & -11.74 & \pm 2.03 & 60.01 & \pm 2.81 \\
SD1 & 33.98 & \pm 1.21 & 3.84 & -31.29 & \pm 1.96 & 41.05 & \pm 3.24 \\
SD2 & 43.76 & \pm 1.53 & 3.93 & -7.42 & \pm 2.14 & 42.17 & \pm 4.56 \\
SD3 & 49.16 & \pm 1.37 & 3.60 & -6.39 & \pm 1.94 & 28.97 & \pm 3.89 \\
\hline
\end{tabular}

a SPAN value was calculated as $\left|\frac{\mathrm{d}_{90 \%}-\mathrm{d}_{10 \%}}{\mathrm{~d}_{50 \%}}\right| .{ }^{\mathrm{b}}$ Unprocessed fenofibrate.

The dissolution profiles of all processed particles are provided in Figure 6. The dissolution efficiencies $\left(\mathrm{DE}_{30 \mathrm{~min}}\right.$ ) for the composite particles prepared by the SA-SD process were $63.69 \%, 60.00 \%$, and $55.84 \%$ for SS1, SS2, and SS3, respectively, while the $\mathrm{DE}_{30}$ min values for the composite particles prepared by the SD process were $28.83 \%, 21.43 \%$, and $18.24 \%$ for SD1, SD2, and SD3, respectively. Although the contact angles of the SD-processed particles (SD1, SD2, and SD3) were smaller than were those of the SA-SD-processed particles, the SA-SD-processed particles (SS1, SS2, and SS3) exhibited a more rapid dissolution rate than did the SD-processed particles. The first reason for this result is likely due to the difference 
in the mean particle sizes between the fenofibrate microparticles prepared by the two different particle formation processes based on the Noyes-Whitney equation [66-68]. Thus, it can be also suggested that there is a limit to enhancing the dissolution rate of poorly water-soluble drugs by improving the wettability without particle size reduction.

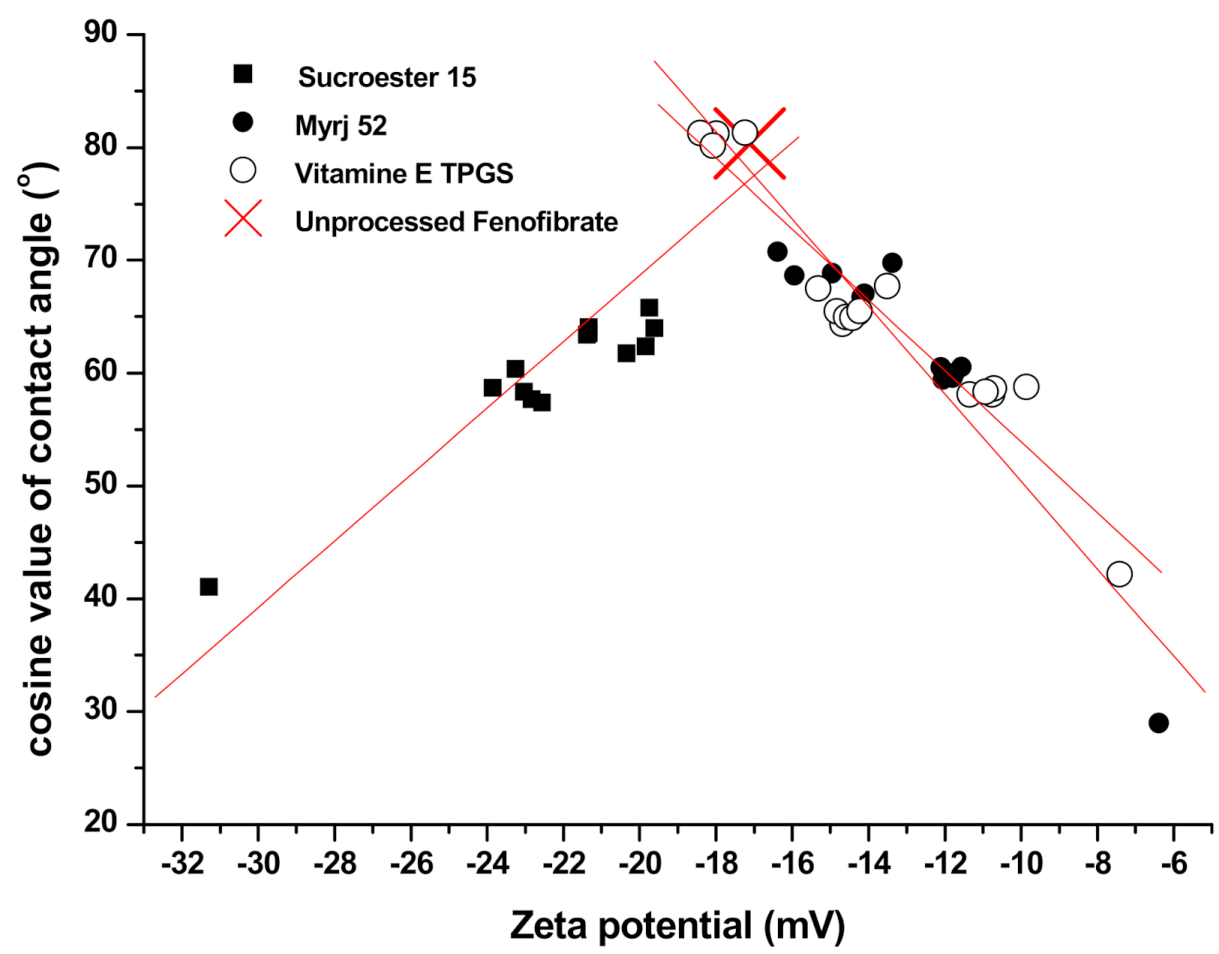

Figure 5. The relationship between zeta potential values and equilibrium contact angles.

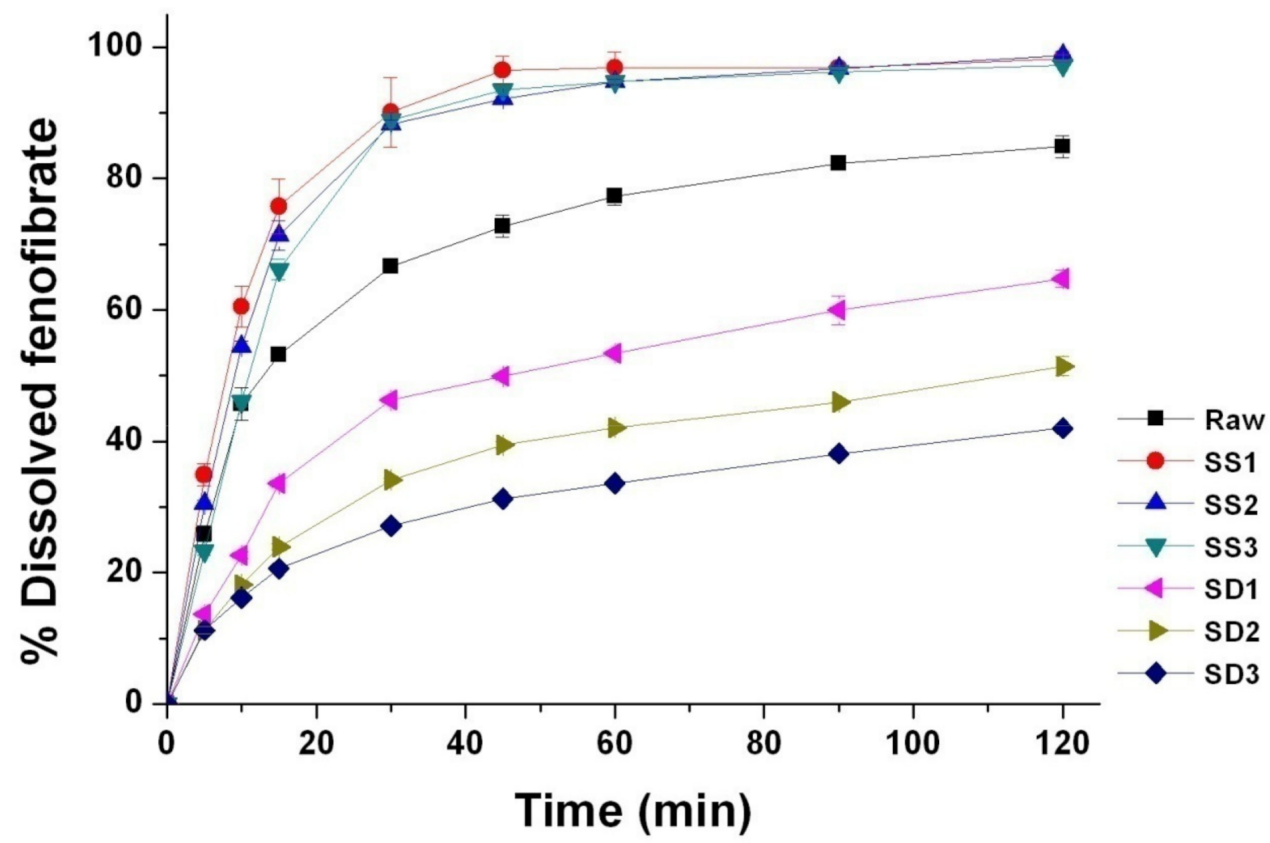

Figure 6. Dissolution profiles of the fenofibrate microcomposite particles with surface-active additives prepared using the SA-SD process and the SD process.

The second presumed cause is the difference in the distribution of surface-active additives between the surface and the inside of the particle matrix. From the results of the 
zeta potential analysis, it was assumed that the significant differences in zeta potential between the SA-SD-processed and the SD-processed microparticles with the same theoretical formulation may be due to the difference in the actual composition of the surface-active additive distributed on the particle surface that directly contacts the water (Figure 7). It is likely that the surface-active additive composition on the surface layer of the SD-processed particles with better wettability would be higher compared to that of the SA-SD-processed composite particles. Additionally, it should be noted that the hydrophilic additive is present theoretically as a minor component in terms of the weight fraction present in the formed fenofibrate/additive microcomposite particles. The result of possessing an excessive additive amount on the surface may indicate that a relatively much smaller amount of additive is distributed within the SD-processed microparticle. Considering that the initial dissolution step can be dominated by the dissolution rate of the hydrophilic additives rather than by poorly water-soluble drugs, the surface-active excipients that are excessively distributed on the surface will become depleted more rapidly by dissolving into the bulk phase medium during the wetting process at the very beginning of dissolution. Immediately afterward, the creation of a surface layer rich in poorly water-soluble fenofibrate will result in a decrease in the dissolution rate. In contrast, the hydrophilic additive molecules can be dispersed homogeneously in the case of the SA-SD-processed composite particles. As shown in Figure 7, when solution droplets are formed during the SD process, the surface active material are arranged at the interface between the droplets and air and, thus, tend to form surface active material-enriched surface of the dried particles $[69,70]$. In contrast, it is estimated that the use of ethanol as a co-solvent with the $\mathrm{SC}-\mathrm{CO}_{2}$ in the SA-SD technology can induce a more homogeneous distribution of surface active material and drug throughout the droplet. In addition, the formation of smaller droplets by the secondary atomization action of $\mathrm{SC}-\mathrm{CO}_{2}$ dissolved inside the droplet may have influenced these results. Thus, the enhanced wettability could be maintained by the constant amount of hydrophilic additive exposed to the dissolution medium throughout the overall dissolution procedure. The carrier-controlled dissolution model suggested by Corrigan [71] described that the dissolution rate of the minor component is determined by that of another component in excess. This theory supports the above hypothesis by considering the dissolution of a binary component system consisting of fenofibrate and surface-active material $[72,73]$.

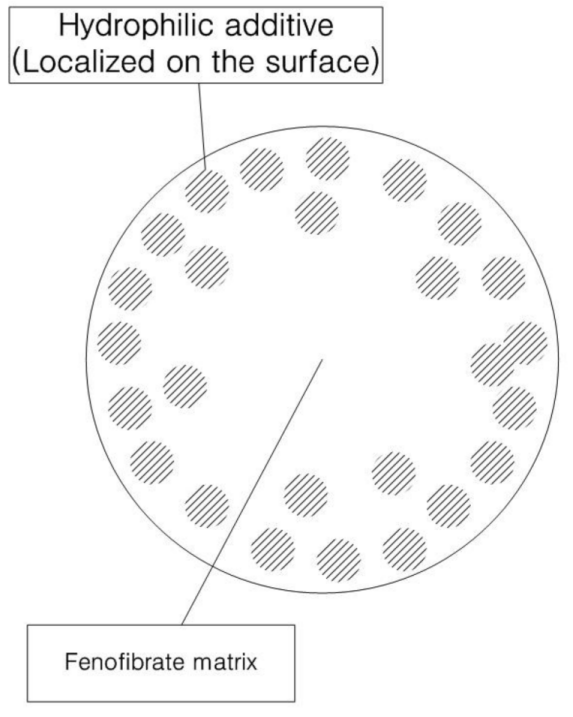

Spray-dried particles

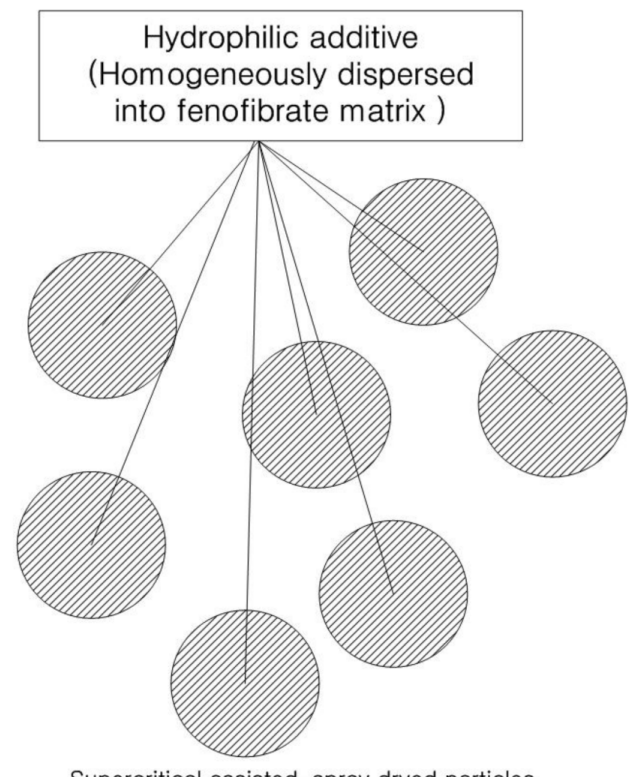

Supercritical assisted-spray dryed particles

Figure 7. The schematic representation of the fenofibrate microparticles prepared using the SA-SD process and the SD process. 
Furthermore, the XPS results confirm that the above assumption is reasonable. XPS was performed to quantify the amount of hydrophilic additives on the particle surfaces of six different binary composite particles. The theoretical and experimentally measured surface compositions of the prepared composite particles are listed in Table 3. The relative surface compositions and surface coverage values for each of the six formulas are listed in Table 4. Each component within the microparticle samples can be analyzed according to the specific ratio between the different elements. Analysis of the relative amounts of the different elements in the pure materials and in the composite particles can help to estimate the surface composition of particles, particularly for the powder samples that are covered with an additive thin layer. The quantification of surface composition can be achieved using the following method.

Table 3. Atomic concentrations (\%) determined by the XPS and theoretical values for the additives used for preparing the fenofibrate microparticles (mean \pm S.D., $n=3$ ).

\begin{tabular}{|c|c|c|c|c|c|c|c|c|c|}
\hline \multirow{4}{*}{$\begin{array}{c}\text { Substance } \\
\text { Fenofibrate } \\
\text { Theory }^{\mathrm{a}}\end{array}$} & \multicolumn{3}{|c|}{ Numbers of Atom } & \multicolumn{6}{|c|}{ Atomic Concentration (\%) } \\
\hline & \multirow{2}{*}{$\begin{array}{c}\mathrm{C} \\
20\end{array}$} & \multirow{2}{*}{$\begin{array}{l}\text { O } \\
4\end{array}$} & \multirow{2}{*}{$\begin{array}{l}\mathrm{Cl} \\
1\end{array}$} & \multicolumn{2}{|c|}{ C1s } & \multicolumn{2}{|c|}{ O1s } & \multicolumn{2}{|c|}{$\mathrm{Cl} 2 p$} \\
\hline & & & & 80.4 & \pm 0.8 & 15.0 & \pm 0.7 & 4.6 & \pm 0.4 \\
\hline & - & - & - & 80.0 & & 16.0 & & 4.0 & \\
\hline Sucroester 15 & 28 & 12 & - & 70.3 & \pm 0.7 & 29.7 & \pm 0.5 & - & \\
\hline Theory $^{\mathrm{a}}$ & - & - & - & 70.0 & & 30.0 & & - & \\
\hline TPGS & 57 & 28 & - & 68.1 & \pm 0.9 & 31.9 & \pm 0.6 & - & \\
\hline Theory $^{a}$ & - & - & - & 67.1 & & 32.9 & & - & \\
\hline Myrj 52 & 122 & 54 & - & 69.9 & \pm 0.7 & 20.1 & \pm 0.4 & - & \\
\hline Theory ${ }^{a}$ & - & - & - & 69.3 & & 30.7 & & - & \\
\hline
\end{tabular}

a The theoretical values for all substances were calculated using the molecular weight and empirical molecular formula.

Table 4. Atomic concentrations (\%) determined by XPS for six different composite particles (mean \pm S.D., $n=3$ ).

\begin{tabular}{ccccccccc}
\hline \multirow{2}{*}{ Formula } & \multicolumn{4}{c}{ Atomic Concentration (\%) } & $\begin{array}{c}\text { Surface Coverage } \\
\text { of Additive (\%) }\end{array}$ & $\begin{array}{c}\text { Surface Excess of } \\
\text { Additive }\end{array}$ \\
\cline { 2 - 7 } & \multicolumn{2}{c}{ C1s } & \multicolumn{2}{c}{ O1s } & \multicolumn{2}{c}{ Cl2p } & & 1.7 \\
SS1 & 77.5 & \pm 0.9 & 16.8 & \pm 0.6 & 3.7 & \pm 0.6 & 8.3 & 1.5 \\
SS2 & 78.7 & \pm 0.6 & 17.2 & \pm 0.4 & 3.6 & \pm 0.3 & 7.5 & 1.3 \\
SS3 & 78.1 & \pm 0.5 & 16.7 & \pm 0.5 & 4.1 & \pm 0.7 & 6.5 & 4.9 \\
SD1 & 77.7 & \pm 0.4 & 19.5 & \pm 0.7 & 2.8 & \pm 0.8 & 24.7 & 4.2 \\
SD2 & 77.9 & \pm 0.8 & 19.7 & \pm 0.3 & 2.4 & \pm 0.9 & 20.8 & 5.6 \\
SD3 & 77.2 & \pm 0.7 & 20.2 & \pm 0.6 & 2.6 & \pm 0.7 & 28.1 & \\
\hline
\end{tabular}

If a particle contains $i$ components, at least one element is required in the sample to estimate the relative component coverage. $n$ is the denotation of elements, and the relative amount of element $n$ in pure component $i$ and sample are denoted as $\mathrm{I}_{\text {component } i}^{\mathrm{n}}$ and $\mathrm{I}_{\text {sample }}^{\mathrm{n}}$ respectively. The $\gamma_{i}$ is the relative coverage of component $i$. The following matrix formula can be used to determine the relative coverage of the different components.

$$
\left(\begin{array}{ccc}
\mathrm{I}_{\text {component 1 }}^{1} & \cdots & \mathrm{I}_{\text {component } i}^{1} \\
\cdots & & \cdots \\
\mathrm{I}_{\text {component 1 }}^{\mathrm{n}} & \cdots & \mathrm{I}_{\text {component } i}^{\mathrm{n}}
\end{array}\right)\left(\begin{array}{c}
\gamma_{1} \\
\ldots \\
\gamma_{i}
\end{array}\right)=\left(\begin{array}{c}
\mathrm{I}_{\text {sample }}^{1} \\
\ldots \\
\mathrm{I}_{\text {sample }}^{\mathrm{n}}
\end{array}\right)
$$

or

$$
\mathrm{I}_{\text {component }} \times \Gamma=\mathrm{I}_{\text {sample }}
$$

The equation is solved by:

$$
\mathrm{I}_{\text {component }} \times \mathrm{I}_{\text {component }}^{-1}=\Gamma
$$


In this study, fenofibrate microcomposite particles are composed of fenofibrate and a hydrophilic additive. Fenofibrate contains 20 atoms of carbon (C), four atoms of oxygen $(\mathrm{O})$, and one atom of chloride $(\mathrm{Cl})$. Sucroester 15 (M.W. 580.71) contained 28 carbon atoms and 12 oxygen atoms. TPGS (M.W. 1513) contained $57 \mathrm{C}$ atoms and $28 \mathrm{O}$ atoms. Myrj 52 contains $122 \mathrm{C}$ atoms and $54 \mathrm{O}$ atoms. The relative amount of element $\mathrm{n}$ from the components was designated $\mathrm{I}_{\text {fenofibrate }}^{\mathrm{n}}$ for fenofibrate and $\mathrm{I}_{\text {additive }}^{\mathrm{n}}$ for each additive.

For each of the common elements $\mathrm{C}$ and $\mathrm{O}$ in the composite particles, the relative amount can be expressed as

$$
\begin{aligned}
& \mathrm{I}_{\text {sample }}^{\mathrm{C}}=\mathrm{I}_{\text {fenofibrate }}^{\mathrm{C}} \times \gamma_{\text {fenofibrate }}+\mathrm{I}_{\text {additive }}^{\mathrm{C}} \times \gamma_{\text {additive }} \\
& \mathrm{I}_{\text {sample }}^{\mathrm{O}}=\mathrm{I}_{\text {fenofibrate }}^{\mathrm{O}} \times \gamma_{\text {fenofibrate }}+\mathrm{I}_{\text {additive }}^{\mathrm{O}} \times \gamma_{\text {additive }}
\end{aligned}
$$

where $\mathrm{I}_{\text {sample }}^{\mathrm{C}}$ and $\mathrm{I}_{\text {sample }}^{\mathrm{O}}$ are the relative amounts of $\mathrm{C}$ and $\mathrm{O}$ in the fenofibrate-additive microparticles, and $\gamma_{\text {fenofibrate }}$ and $\gamma_{\text {additive }}$ are the fractions of the area covered with fenofibrate and the additive, respectively. By reducing two linear equations with two variables, $\gamma_{\text {fenofibrate }}$ and $\gamma_{\text {additive }}$ were calculated [74].

The calculated surface coverage values of each formula were $8.3 \%, 7.5 \%, 6.5 \%, 24.7 \%$, $20.8 \%$, and $28.1 \%$ for SS1, SS2, SS3, SD1, SD2, and SD3, respectively. As expected, it is clear that the surface-active additive incorporated in the fenofibrate microparticles produced by the SD process is more localized on the surface of particles compared to that of SASD-processed microparticles. As can be observed in Figure 6 and Table 2, the use of a hydrophilic additive altered the surface characteristics, such as zeta potential and contact angle. To investigate the relationship between the surface coverage of the additive and the wettability of the fenofibrate-additive microcomposite particles, the surface coverage values for all composite particles were plotted with the zeta potential and the contact angles, respectively (Figure 8a,b). Linear correlations were observed (Figure 8). These linear relationships also support the assumption that the hydrophilic additive incorporated into a composite particle produced by the SD process is localized on the particle surface.

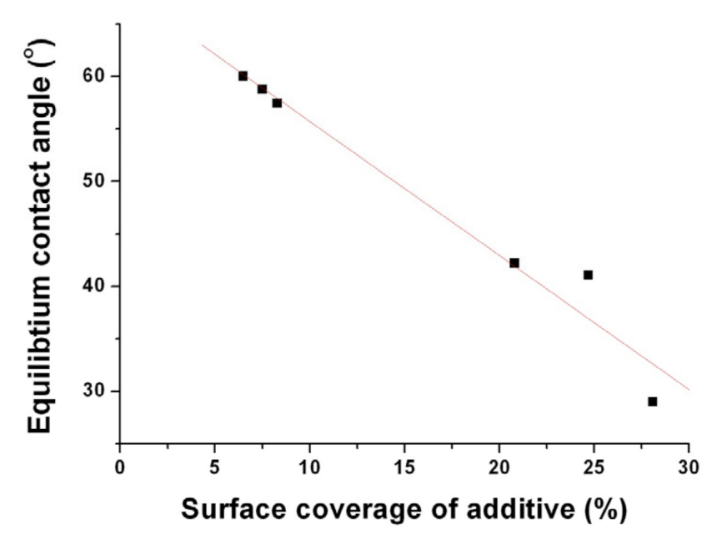

(a)

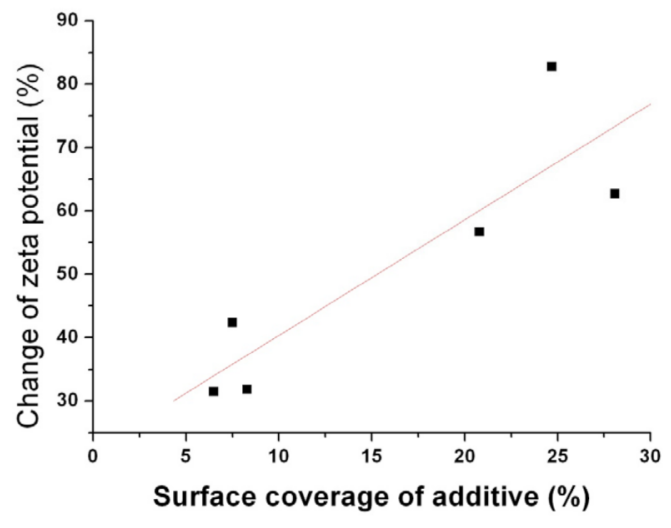

(b)

Figure 8. The relationships (a) between the surface coverage (\%) of the additive and the equilibrium contact angle and (b) between the surface coverage (\%) of the additive and the $\%$ change of the zeta potential.

Based on the data described above, it is suggested that the drying kinetics of the SA-SD process and the conventional SD process are different. In the SD process, the driving force for droplet formation is the pneumatic atomization of air. In contrast, fine droplet size was achieved by the combination of atomizing air with $\mathrm{CO}_{2}$ in the SA-SD process. Thus, the rapid evaporation and mass transfer of ethanol that was used as solvent from the sprayed droplet occurred in the SA-SD process due to the difference in the spray droplet size and the heated atomization air (Figure 1b). Based on the introduction of $\mathrm{CO}_{2}$ for the SA-SD process, 
fenofibrate microparticles possessing mean particle sizes ranging from 1.86-2.17 $\mu \mathrm{m}$ could be obtained from the SA-SD process. Additionally, due to the rapid evaporation of the solvent, fenofibrate microparticles possessing a homogeneous distribution of surface-active additives could be produced by the SA-SD process.

To evaluate the effect of physical modifications, such as the particle size reduction and the improvement of the wettability on the enhancement of the dissolution rate, $\mathrm{DE}_{30 \text { min }}$ values for all processed particles were plotted with the mean particle size and contact angle, respectively (Figures 9 and 10). As shown in Figure 9a, in the case of particle size reduction without the addition of a hydrophilic surfactant, the enhancement of the dissolution rate was not observed. However, a dramatic enhancement in the dissolution rate was observed for the SA-SD-processed fenofibrate microparticles with surface-active excipients. The relationship between the dissolution efficiency and contact angle is presented in Figure $9 \mathrm{~b}$. The same trend was observed in the correlation study between the contact angle and the dissolution efficiency. Consequently, particle size reduction and improvement of the wettability must be achieved simultaneously to improve the dissolution rate of fenofibrate.

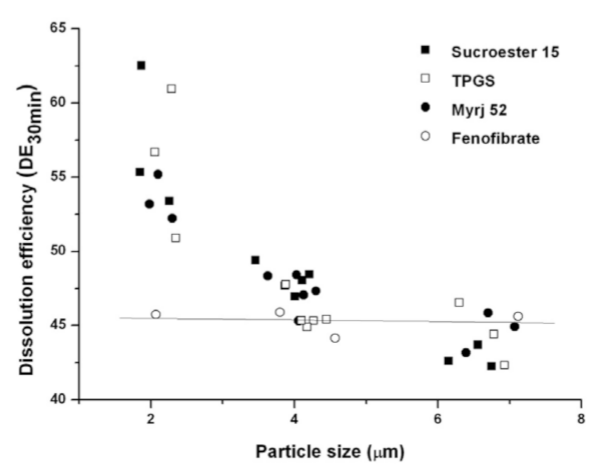

(a)

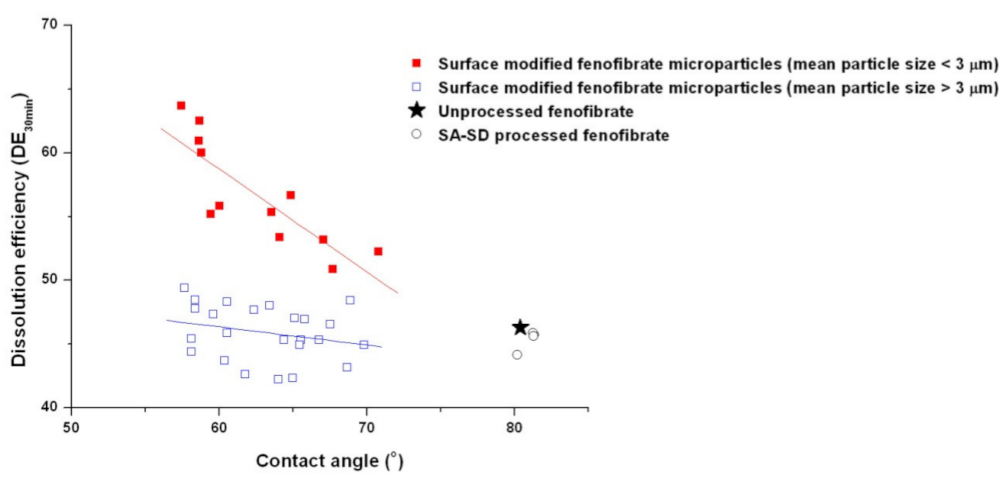

(b)

Figure 9. Scatter plots indicating the relationship of the dissolution efficiency versus (a) the mean particle size and (b) the wettability.

\subsection{Pharmacokinetic (PK) Profile of Fenofibrate Microparticles in Sprague-Dawley Rats}

To investigate the effect of the enhanced dissolution rate of the SA-SD-processed fenofibrate/additive particles on the oral bioavailability of fenofibrate, pharmacokinetic evaluations following an oral dose of $50 \mathrm{mg} / \mathrm{kg}$ of unprocessed fenofibrate and of the SA-SD processed (SS1, SS2, and SS3) and the SD-processed particles (SD1, SD2, and SD3) were performed on male Sprague-Dawley rats. Figure 10 presents the pharmacokinetic profiles for each sample, and the pharmacokinetic parameters following noncompartmental analysis are summarized in Table 5. The fenofibrate/additive composite particles from the SA-SD process significantly increased the $\mathrm{AUC}_{0-12 \mathrm{~h}}$ and $\mathrm{C}_{\max }$ compared to those values after treatment with unprocessed fenofibrate. Unfortunately, the particles from the SD process exhibited no differences compared to the results obtained from the unprocessed fenofibrate. Fenofibrate is a BCS class II drug possessing a high dose number [64,75]. Thus, it is expected that enhanced oral bioavailability would be observed in the case of SA-SD-processed fenofibrate microparticles. 


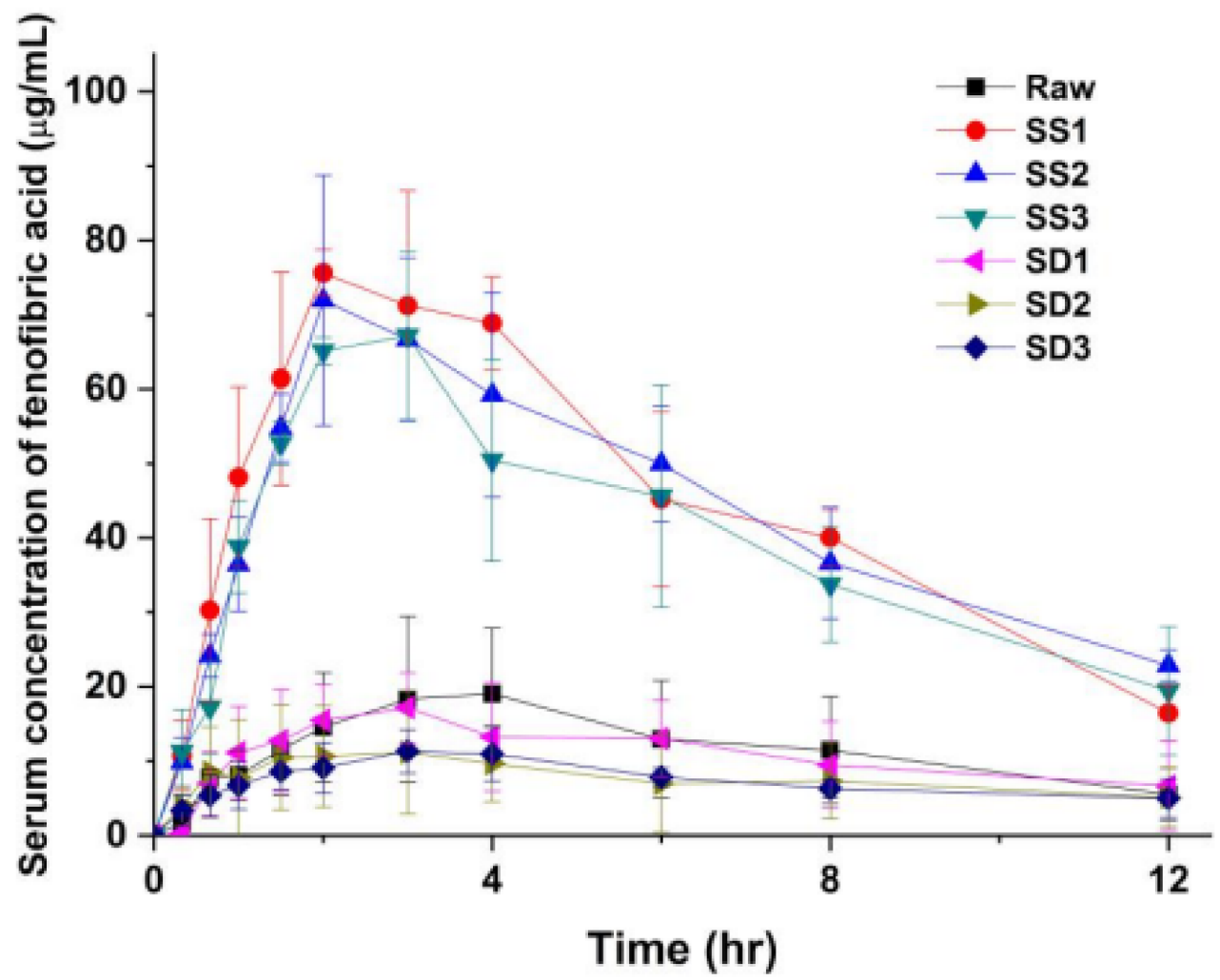

Figure 10. Serum concentration-time profiles of fenofibric acid after single dosing peroral administration of $50 \mathrm{mg} / \mathrm{kg}$ in rats. Six different formulations were tested: SS1, SS2, SS3, SD1, SD2, and SD3 (mean \pm S.D., $n=4$ ).

Table 5. Pharmacokinetic parameters of unprocessed fenofibrate and the SA-SD-processed and the SD-processed fenofibrate-additive microparticles after oral administration in Sprague-Dawley rats (mean \pm S.D.; $n=4$ ).

\begin{tabular}{|c|c|c|c|c|c|c|}
\hline \multirow[b]{2}{*}{$\begin{array}{l}\text { Unprocessed } \\
\text { Fenofibrate }\end{array}$} & \multicolumn{2}{|c|}{$\begin{array}{l}\mathrm{AUC}_{0-12 \mathrm{~h}} \\
(\mu \mathrm{g} \cdot \mathrm{h} / \mathrm{mL})\end{array}$} & \multicolumn{2}{|c|}{$C_{\max }(\mu \mathrm{g} / \mathrm{mL})$} & \multicolumn{2}{|c|}{$\mathrm{T}_{\max }(\mathrm{h})$} \\
\hline & 139.1 & \pm 74.4 & 19.8 & \pm 10.1 & 3.5 & $\pm \mathbf{0 . 6}$ \\
\hline SS1 & 537.4 & \pm 90.1 & 77.8 & \pm 6.2 & 2.5 & \pm 0.6 \\
\hline SS2 & 519.0 & \pm 65.5 & 74.9 & \pm 14.3 & 2.8 & \pm 1.0 \\
\hline SS3 & 475.1 & \pm 96.8 & 70.2 & \pm 8.9 & 2.5 & \pm 0.6 \\
\hline SD1 & 129.8 & \pm 59.0 & 17.8 & \pm 5.3 & 3.5 & \pm 1.0 \\
\hline SD2 & 92.3 & \pm 56.6 & 11.8 & \pm 6.7 & 3.3 & \pm 0.6 \\
\hline SD3 & 89.2 & \pm 24.9 & 12.0 & \pm 3.6 & 3.5 & \pm 0.6 \\
\hline
\end{tabular}

The administration of unprocessed fenofibrate resulted in an $\mathrm{AUC}_{0-12 \mathrm{~h}}$ value of $139.1 \pm 74.4 \mu \mathrm{g} \cdot \mathrm{h} / \mathrm{mL}$ and $\mathrm{C}_{\max }$ of $19.8 \pm 10.1 \mu \mathrm{g} / \mathrm{mL}$. When the same dose of SASD processed fenofibrate microparticles was administrated, the systemic exposure to fenofibrate was increased significantly as reflected in $\mathrm{AUC}_{0-12 \mathrm{~h}}$ values of $537.4 \pm 90.1$, $519.0 \pm 65.5$, and $475.1 \pm 96.8 \mu \mathrm{g} \cdot \mathrm{h} / \mathrm{mL}$ for SS1, SS2, and SS3, respectively. These pharmacokinetic profiles of fenofibrate in Sprague-Dawley rats reflect the in vitro dissolution rate enhancement achieved by the SA-SD process and the addition of hydrophilic additives. This assumption is also supported by the decrease in $\mathrm{T}_{\max }(3.6 \pm 0.6 \mathrm{~h}$ for unprocessed fenofibrate, $2.5 \pm 0.6,2.8 \pm 1.0$, and $2.5 \pm 0.6 \mathrm{~h}$ for SS1, SS2, and SS3, respectively). The administration of the SD-processed fenofibrate microparticles resulted in $\mathrm{AUC}_{0-12 \mathrm{~h}}$ values of $129.8 \pm 59.0,92.3 \pm 56.6$, and $89.2 \pm 24.9$ for SD1, SD2, and SD3, respectively, thus 
indicating significantly lower bioavailability compared to that of SA-SD-processed microcomposite particles. Additionally, the determined $\mathrm{C}_{\max }$ values were in the order of SS1 $>$ SS2 $>$ SS3 $>$ unprocessed fenofibrate $>$ SD1 $>$ SD2 $\fallingdotseq$ SD3. From the results of the pharmacokinetic evaluation, it was demonstrated that the oral bioavailability of fenofibrate was severely affected by the in vitro dissolution rate of fenofibrate microparticles.

To investigate the relationship between the in vitro dissolution rate and oral bioavailability of fenofibrate, dissolution efficiency values were plotted with $\mathrm{AUC}_{0-12 \mathrm{~h}}$ values and $\mathrm{C}_{\max }$ values, respectively (Figure 11a,b). These figures clearly illustrate the correlation between the oral bioavailability of fenofibrate and the in vitro dissolution rate. At dissolution efficiencies $\left(\mathrm{DE}_{30 \mathrm{~min}}\right)$ ranging from $18.2 \%$ to $63.7 \%$, the $\mathrm{AUC}_{0-12 \mathrm{~h}}$, and $\mathrm{C}_{\max }$ increased with dissolution efficiency, and the relationships were almost linear for both $\mathrm{AUC}_{0-12 \mathrm{~h}}$ and $C_{\max }$. These results strongly suggest that the enhanced dissolution rate of fenofibrate microparticles could provide an efficient means to improve the oral bioavailability of fenofibrate.

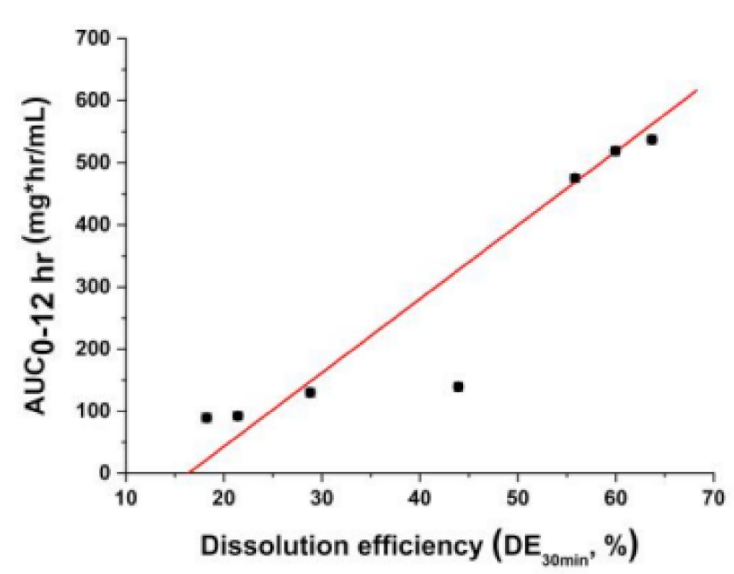

(a)

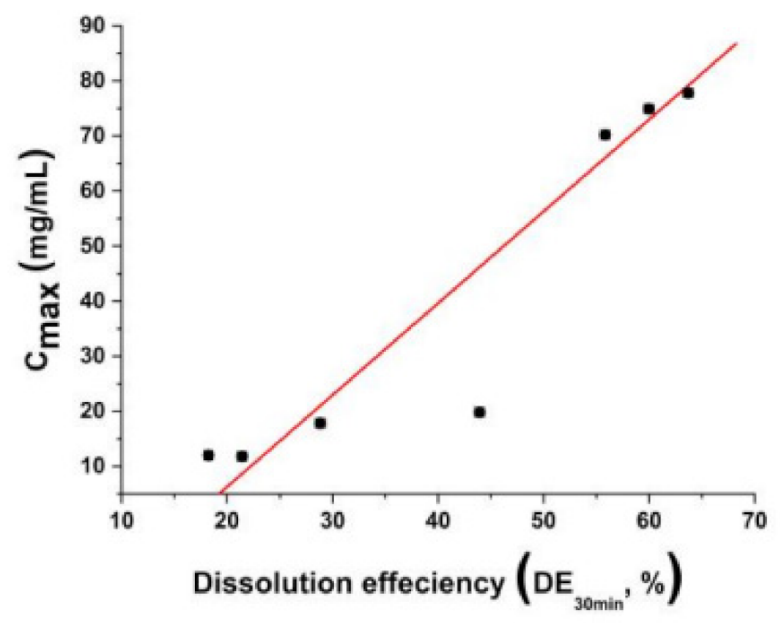

(b)

Figure 11. Relationship (a) between dissolution efficiency and $\mathrm{AUC}_{0-12 \mathrm{~h}}$ and (b) between dissolution efficiency and $\mathrm{C}_{\mathrm{max}}$. A linear fit is presented as a dashed line that is intended as a guide for the eye and to indicate the relationship presented in the plots.

\subsection{Pharmacodynamic (PD) Therapeutic Efficacy in Sprague-Dawley Rats}

Fenofibrate is a drug that is used to treat hyperlipidemia and is reportedly effective at low doses [76]. The lipid-lowering effect of fenofibrate is known to be dose-dependent. Thus, in the present study the effect of the dissolution rate enhancement on the pharmacodynamic effect of fenofibrate was evaluated in Sprague-Dawley rats. Triton-induced hyperlipidemic rats were used to evaluate the hypolipidemic effect of fenofibrate microparticles. Triton-induced hyperlipidemia can be divided into two stages that include phase I and phase II. In phase I, serum lipid levels were increased and peaked after approximately $24 \mathrm{~h}$ of Triton injection. Phase II was the period for recovering normal lipid levels and lasted another $24 \mathrm{~h}$. As fenofibrate possesses a long biological half-life (approximately $20 \mathrm{~h}$ ), the lipid-lowering effect of the fenofibrate microparticles was monitored for $48 \mathrm{~h}$ after the Triton injection.

The serum lipid profiles in phase I ( $24 \mathrm{~h})$ and phase II $(48 \mathrm{~h})$ for all tested samples are presented in Table 6. Within the phase I period, unprocessed fenofibrate reduced serum triglyceride and cholesterol levels by $54.0 \%$ and $70.8 \%$, respectively. In the case of the groups that were administered SA-SD-processed fenofibrate microparticles, serum triglyceride and cholesterol levels were reduced by $81.3-91.3 \%$ and $85.9-91.6 \%$, respectively. 
As expected, no drastic enhancement of the in vivo performance of the SD-processed fenofibrate microparticles was observed. From the serum lipid profiles obtained in phase II, the SA-SD group maintained the lipid-lowering effect (76.6-83.7\% inhibition for serum triglyceride and $86.9-93 \%$ inhibition for serum cholesterol). These results suggest that the improved dissolution rate of the SA-SD-processed fenofibrate microparticles could enhance the lipid-lowering effect rate in addition to the oral bioavailability of fenofibrate.

Table 6. The serum lipid profiles in phase I $(24 \mathrm{~h})$ and phase II ( $48 \mathrm{~h})$ for all tested samples (mean \pm S.D., $n=4)^{\text {a }}$.

\begin{tabular}{|c|c|c|c|c|c|c|c|c|}
\hline \multirow{3}{*}{$\begin{array}{l}\text { Group } \\
\text { Control }\end{array}$} & \multicolumn{4}{|c|}{ Phase I (After 24 h) } & \multicolumn{4}{|c|}{ Phase II (After 48 h) } \\
\hline & \multicolumn{2}{|c|}{$\begin{array}{c}\text { Total Cholesterol } \\
\text { (mg/dL) }\end{array}$} & \multicolumn{2}{|c|}{ Triglycerides (mg/dL) } & \multicolumn{2}{|c|}{$\begin{array}{c}\text { Total Cholesterol } \\
\text { (mg/dL) }\end{array}$} & \multicolumn{2}{|c|}{ Triglycerides (mg/dL) } \\
\hline & 70.4 & \pm 9.5 & 131.7 & \pm 6.7 & 68.9 & \pm 10.6 & 109.2 & \pm 4.9 \\
\hline Triton & 256.7 & \pm 9.0 & 370.1 & \pm 7.5 & 141.1 & \pm 6.2 & 221.1 & \pm 4.5 \\
\hline Unprocessed & 124.7 & $\pm 24.5(70.8)$ & 241.4 & $\pm 3.7(54.0)$ & 88.7 & $\pm 9.2(72.6)$ & 159.8 & $\pm 7.1(54.8)$ \\
\hline SS1 & 86.1 & $\pm 8.6(91.6)$ & 152.4 & $\pm 2.5(91.3)$ & 73.9 & $\pm 4.0(93.0)$ & 127.5 & $\pm 3.9(83.7)$ \\
\hline SS2 & 89.6 & $\pm 10.8(89.7)$ & 173.9 & $\pm 10.5(82.3)$ & 74.1 & $\pm 5.9(92.8)$ & 139.6 & $\pm 12.2(72.9)$ \\
\hline SS3 & 96.7 & $\pm 4.7(85.9)$ & 170.8 & $\pm 4.0(83.6)$ & 78.3 & $\pm 9.2(86.9)$ & 135.4 & $\pm 3.3(76.6)$ \\
\hline SD1 & 138.1 & $\pm 1.3(63.6)$ & 231.9 & $\pm 5.3(58.0)$ & 93.6 & $\pm 9.8(65.8)$ & 148.7 & $\pm 5.8(64.7)$ \\
\hline SD2 & 146.1 & $\pm 2.3(59.3)$ & 243.9 & $\pm 4.1(52.9)$ & 91.7 & $\pm 14.0(68.4)$ & 165.8 & $\pm 7.6(49.5)$ \\
\hline SD3 & 146.3 & $\pm 23.8(59.2)$ & 249.7 & $\pm 6.4(50.5)$ & 102.9 & $\pm 8.5(52.9)$ & 159.8 & $\pm 5.1(54.8)$ \\
\hline
\end{tabular}

${ }^{a}$ Data in parentheses represent \% inhibition calculate as follows; (1-((serum lipid level of each sample group)-(serum lipid level of control group $)) /(($ serum lipid level of Triton group)-(serum lipid level of control) $)) \times 100$.

\section{Conclusions}

In this study, the SA-SD particle formation technique was applied to functionalize microcomposite particles of fenofibrate (a poorly water-soluble drug) with surface-active additives, and these particles were then compared to those prepared using a conventional SD process. The SA-SD process resulted in a significant decrease in mean particle size compared to the sizes of unprocessed fenofibrate particles and microparticles prepared using the SD process. In particular, more homogeneous composite particles were obtained by the SA-SD process compared to those prepared using the SD process. Additionally, it was also demonstrated that the particle size reduction and the improvement of the wetting property enabled by SA-SD processing with surface-active additives can lead to improved in vitro and in vivo performances in regard to the dissolution rate, the oral bioavailability, and, consequently, the lipid-lowering effect of fenofibrate. In contrast, SD processing did not reduce the size of fenofibrate microcomposite particles, although the wettability of particles was greatly improved. Additionally, the creation of a surface layer that is rich in poorly water-soluble fenofibrate after rapid depletion of excessive surface-active additives distributed locally on the surface of SD-processed particles resulted in a decrease in the dissolution rate. This negative effect on dissolution contributed to the absence of a marked effect on the improvement of PK parameters and PD therapeutic efficacy in vivo. Therefore, it was concluded that the SA-SD process is a superior tool for the micronization of poorly water-soluble drugs to improve their pharmaceutical performance in regard to both PK and PD.

Supplementary Materials: The following are available online at https: / www.mdpi.com/article / 10.3390/pharmaceutics13122061/s1, Figure S1: Chemical Structures of (a) fenofibrate (MW 360.84), (b) d- $\alpha$-tocopheryl polyethelyene glycol 1000 succinate (TPGS, MW 1513, hydrophilic-lipophilic balance (HLB) 13.2), (c) polyoxyethylene 40 stearate (Myrj 52, MW 2046.58, HLB 16.9) and (d) sucrose monopalmitate (sucroester 15, MW 580.71, HLB 15), Figure S2: Significant standardized main effects on the mean particle size, SPAN, and $\mathrm{DE}_{30}$ min estimated from BBD using Sucroester 15, Figure S3: Significant standardized main effects on the mean particle size, SPAN, and $\mathrm{DE}_{30 \mathrm{~min}}$ estimated from BBD using TPGS, Figure S4: Significant standardized main effects on the mean particle size, SPAN, and $\mathrm{DE}_{30 \text { min }}$ estimated from BBD using Myrj 52, Figure S5: Response surface plots constructed by the BBD using Sucroester 15 as an additive, Figure S6: Response surface plots 
constructed by the BBD using TPGS 15 as an additive, Figure S7: Response surface plots constructed by the BBD using Myrj 52 as an additive, Figure S8: The SEM micrographs of the SA-SD processed fenofibrate/Sucroester 15 microcomposite particles, Figure S9: The SEM micrographs of the SA-SD processed fenofibrate/TPGS 15 microcomposite particles, Figure S10: The SEM micrographs of the SA-SD processed fenofibrate/Myrj 52 microcomposite particles, Figure S11: The cumulative particle size distributions of the SA-SD processed fenofibrate/Sucroester 15 microcomposite particles, Figure S12: The cumulative particle size distributions of the SA-SD processed fenofibrate/TPGS 15 microcomposite particles, Figure S13: The cumulative particle size distributions of the SA-SD processed fenofibrate/Myrj 52 microcomposite particles, Figure S14: Dissolution profiles of the SASD processed fenofibrate-additive microcomposite particles (fenofibrate/Sucroester 15), Figure S15: Dissolution profiles of profiles of the SA-SD processed fenofibrate-additive microcomposite particles (fenofibrate/TPGS), Figure S16: Dissolution profiles of profiles of the SA-SD processed fenofibrateadditive microcomposite particles (fenofibrate/Myrj 52), Table S1: Experimental runs and observed responses in preparation of fenofibrate/Sucroester 15 microparticles, Table S2: Experimental runs and observed responses in preparation of fenofibrate/TPGS microparticles, Table S3: Experimental runs and observed responses in preparation of fenofibrate/Myrj 52 microparticles, Table S4: Regression equations of the best fitted models, Table S5: Zeta potential values and equilibrium contact angle of the SA-SD processed fenofibrate/Sucroester 15 composite particles, Table S6: Zeta potential values and equilibrium contact angle of the SA-SD processed fenofibrate/TPGS composite particles, Table S7: Zeta potential values and equilibrium contact angle of the SA-SD processed fenofibrate/Myrj 52 composite particles.

Author Contributions: Conceptualization, J.-S.K.; H.P.; M.-S.K. and S.-J.H.; Formal analysis, J.-S.K. and E.-S.H.; Funding acquisition, H.P.; K.-T.K.; M.-S.K. and S.-J.H.; Investigation, J.-S.K.; H.P.; Methodology, J.-S.K.; E.-S.H. and K.-T.K.; Supervision, M.-S.K. and S.-J.H.; Writing-original draft, J.-S.K., H.P. and E.-S.H.; Writing-review \& editing, J.-S.K.; H.P.; K.-T.K.; M.-S.K. and S.-J.H. All authors have read and agreed to the published version of the manuscript.

Funding: This research was supported by the Basic Science Research Program through the National Research Foundation of Korea funded by the Ministry of Education (2016R1A6A1A03007648). This work was supported by the Mid-Career Researcher Program (NRF-2021R1A2C2008834). This research was supported by the Basic Science Research Program through the National Research Foundation of Korea funded by the Ministry of Education (NRF-2018R1A6A1A03023718). This work was supported by the National Research Foundation of Korea (NRF) grant funded by the Korea government (MSIT) (No. 2020R1A2C4002166). This research was supported by Basic Science Research Program through the National Research Foundation of Korea (NRF) funded by the Ministry of Education (No. 2020R1I1A1A01074378).

Institutional Review Board Statement: The study was conducted according to the guidelines of the Care and Use of Laboratory Animals of Korea, and approved by the Institutional Review Board of the nonclinical contract research organization, KPC laboratory (protocol code: I-1708186, date of approval: 29 August 2017).

Conflicts of Interest: Jeong-Soo Kim is employed at Dong-A ST Co. Jeong-Soo Kim has no economical or commercial interest to disclaim. The other authors declare no conflict of interest.

\section{References}

1. Cunha, M.S.S.; Martinez-Pacheco, R.; Landin, M. Dissolution rate enhancement of the novel antitumoral beta-lapachone by solvent change precipitation of microparticles. Eur. J. Pharm. Biopharm. 2008, 69, 871-877. [CrossRef]

2. Huang, Q.P.; Wang, J.X.; Chen, G.Z.; Shen, Z.G.; Chen, J.F.; Yun, J. Micronization of gemfibrozil by reactive precipitation process. Int. J. Pharm. 2008, 360, 58-64. [CrossRef]

3. Kiio, T.M.; Park, S. Physical properties of nanoparticles do matter. J. Pharm. Investig. 2021, 51, 35-51. [CrossRef]

4. Kim, N.A.; Oh, H.K.; Lee, J.C.; Choi, Y.H.; Jeong, S.H. Comparison of solubility enhancement by solid dispersion and micronized butein and its correlation with in vivo study. J. Pharm. Investig. 2021, 51, 53-60. [CrossRef]

5. Erdoğar, N.; Akkın, S.; Nielsen, T.T.; Özçelebi, E.; Erdoğdu, B.; Nemutlu, E.; İskit, A.B.; Bilensoy, E. Development of oral aprepitantloaded chitosan-polyethylene glycol-coated cyclodextrin nanocapsules: Formulation, characterization, and pharmacokinetic evaluation. J. Pharm. Investig. 2021, 51, 297-310. [CrossRef]

6. Gautam, M.; Kim, J.O.; Yong, C.S. Fabrication of aerosol-based nanoparticles and their applications in biomedical fields. J. Pharm. Investig. 2021, 51, 1-15. [CrossRef] 
7. Kim, D.-H.; Lee, S.-E.; Pyo, Y.-C.; Tran, P.; Park, J.-S. Solubility enhancement and application of cyclodextrins in local drug delivery. J. Pharm. Investig. 2020, 50, 17-27. [CrossRef]

8. Ha, E.-S.; Lee, S.-K.; Choi, D.H.; Jeong, S.H.; Hwang, S.-J.; Kim, M.-S. Application of diethylene glycol monoethyl ether in solubilization of poorly water-soluble drugs. J. Pharm. Investig. 2020, 50, 231-250. [CrossRef]

9. Porta, G.; Reverchon, E. Engineering powder properties by supercritical fluid for optimum drug delivery. Part two: Supercriticalassisted atomisation. BioProcess. Imt. 2005, 3, 54-60.

10. Park, H.; Ha, E.-S.; Kim, M.-S. Surface modification strategies for high-dose dry powder inhalers. J. Pharm. Investig. 2021, 51, 1-34. [CrossRef]

11. Krukonis, V. Supercritical fluid nucleation of difficult-to-comminute solids. In Proceedings of the Annual Meeting AIChE, San Francisco, CA, USA, 25-30 November, 25-30 November 1984.

12. Phillips, E.; Stella, V. Rapid expansion from supercritical solutions: Application to pharmaceutical processes. Int. J. Pharm. 1993, 94, 1-10. [CrossRef]

13. Matson, D.W.; Fulton, J.L.; Petersen, R.C.; Smith, R.D. Rapid expansion of supercritical fluid solution: Solute formation of powders. Thin films and fibers. Ind. Eng. Chem. Res. 1987, 26, 2298-2306. [CrossRef]

14. Jung, J.; Perrut, M. Particle design using supercritical fluids: Literature and patent survey. J. Supercrit. Fluids 2001, 20, 179-219. [CrossRef]

15. Sane, A.; Thies, M.C. Effect of material properties and processing conditions on RESS of poly(l-lactide). J. Supercrit. Fluids 2007, 40, 134-143. [CrossRef]

16. Matson, D.W.; Fulton, J.L.; Petersen, R.C.; Smith, R.D. Production of powders and Films from Supercritical Solutions. J. Mater. Sci. 1987, 22, 1919-1928. [CrossRef]

17. Petersen, R.C.; Matson, D.W.; Smith, R.D. The Formation of Polymer Fibers from the Rapid Expansion of Supercritical Fluid Solutions. Polym. Eng. Sci. 1987, 27, 1963-1967. [CrossRef]

18. Yang, T.M.; Su, C.S.; Li, J.S.; Lu, K.T.; Yeh, T.F. Recrystallization and micronization of p-toluenesulfonamide using the rapid expansion of supercritical solution (RESS) process. Crystals 2019, 9, 449. [CrossRef]

19. Meziani, M.; Pathak, P.; Beacham, F.; Allard, L.; Sun, Y. Nanoparticle formation in rapid expansion of water-in-supercritical carbon dioxide microemulsion into liquid solution. J. Supercrit. Fluids 2005, 34, 91-97. [CrossRef]

20. Young, T.; Johnston, K.; Pace, G.; Mishra, A. Phospholipid-stabilized nanoparticles of cyclosporine a by rapid expansion from supercritical to aqueous solution. AAPS PharmSciTech 2004, 5, 70-85.

21. Young, T.J.; Mawson, S.; Johnston, K.P.; Henriksen, I.B.; Pace, G.W.; Mishra, A.K. Rapid expansion from supercritical to aqueous solution to produce submicron suspensions of water-insoluble drugs. Biotechnol. Prog. 2000, 16, 402-407. [CrossRef]

22. Chattopadhyay, P.; Gupta, R.B. Supercritical $\mathrm{CO}_{2}$ based production of magnetically responsive micro- and nano-particles for drug targeting. Ind. Eng. Chem. Res. 2002, 41, 6049-6058. [CrossRef]

23. Seckner, A.J.; McClellan, A.K.; McHugh, M.A. High solution behavior of the polymer-toluene-ethane system. AIChE 1988, 34, 9-16. [CrossRef]

24. McHugh, M.A.; McClellan, T.L. Seperating polymer solutions with supercritical fluids. Macromolecules 1985, $18,674-681$. [CrossRef]

25. Hanna, M.; York, P. Method And Apparatus For The Formation Of Particles. WO Patent 1995/001221, 12 January 1995.

26. Moshashaee, S.; Bisrat, M.; Forbes, R.; Quinn, E.; Nyqvist, H.; York, P. Supercritical fluid processing of proteins: Lysozyme precipitation from aqueous solution. J. Pharm. Pharmacol. 2003, 55, 185-192. [CrossRef]

27. Graser, F.; Wickenhaeuser, G. Conditioning of finely divided crude organic pigments. U.S. Patent 4,451,654, 20 September 1982.

28. Kazarian, S. Polymer processing with supercritical fluids. Polym. Sci. Ser. C 2000, 42, 78-101.

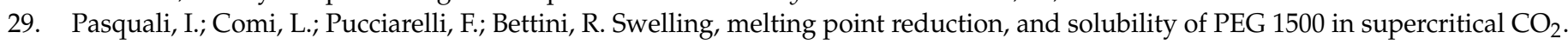
Int. J. Pharm. 2008, 356, 76-81. [CrossRef]

30. Ventosa, N.; Sala, S.; Veciana, J. DELOS process: A crystallization technique using compressed fluids: 1. Comparison to the GAS crystallization method. J. Supercrit. Fluids 2003, 26, 33-45. [CrossRef]

31. Weidner, E.; Petermann, M.; Blatter, K.; Rekowski, V. Manufacture of powder coatings by spraying of gas-enriched melts. Chem. Eng. Technol. 2001, 24, 529-533. [CrossRef]

32. Sievers, R.; Huang, E.; Villa, J.; Engling, G.; Brauer, P. Micronization of water-soluble or alcohol-soluble pharmaceuticals and model compounds with a low-temperature Bubble Dryer ${ }^{\circledR}$. J. Supercrit. Fluids 2003, 26, 9-16. [CrossRef]

33. Reverchon, E. Supercritical-assisted atomization to produce micro-and/or nanoparticles of controlled size and distribution. Ind. Eng. Chem. Res. 2002, 41, 2405-2411. [CrossRef]

34. Cho, W.; Kim, M.-S.; Jung, M.-S.; Park, J.; Cha, K.-H.; Kim, J.-S.; Park, H.J.; Alhalaweh, A.; Velaga, S.P.; Hwang, S.-J. Design of salmon calcitonin particles for nasal delivery using spray-drying and novel supercritical fluid-assisted spray-drying processes. Int. J. Pharm. 2015, 478, 288-296. [CrossRef]

35. Hwang, S.J.; Kim, M.S.; Kim, J.S.; Cha, K.H.; Cho, W.K.; Park, J.S.; Seo, S.J. Manufacturing Method and Apparatus of Ultrafine Particles Having Uniform Particle Size Distribution. U.S. Patent 8,734,830, 27 May 2014.

36. Kim, J.A.; Paxton, T.E.; Tomasko, D.L. Microencapsulation of naproxen using rapid expansion of supercritical solutions. Biotechnol. Prog. 1996, 12, 650-661. [CrossRef] 
37. Falk, R.F.; Randolph, T.W. Process variable implications for residual solvent removal and polymer morphology in the formation of Gentamycin-loaded poly(l-lactide) microparticles. Pharm. Res. 1998, 15, 1233-1237. [CrossRef]

38. Ghaderi, R.; Artursson, P.; Carlfors, J. Preparation of biodegradable microparticles using solution-enhanced dispersion by supercritical fluids (SEDS). Pharm. Res. 1999, 16, 676-681. [CrossRef]

39. Elvassore, N.; Baggio, M.; Pallado, P.; Bertucco, A. Production of insulin-loaded poly(ethylene glycol)/poly(l-lactide)(PEG/PLA) nanoparticles by gas antisolvent techniques. J. Pharm. Sci. 2001, 90, 1628-1636. [CrossRef]

40. Corrigan, O.; Crean, A. Comparative physicochemical properties of hydrocortisone-PVP composites prepared using supercritical carbon dioxide by the GAS anti-solvent recrystallization process, by coprecipitation and by spray drying. Int. J. Pharm. 2002, 245, 75-82. [CrossRef]

41. Sethia, S.; Squillante, E. Physicochemical characterization of solid dispersion of carbamazepine formulated by supercritical carbon dioxide and conventional solvent evaporation method. J. Pharm. Sci. 2002, 91, 1948-1957. [CrossRef]

42. Snavely, W.; Subramaniam, B.; Rajewski, R.; Defelippis, M. Micronization of insulin from halogenated alcohol solution using supercritical carbon dioxide as an antisolvent. J. Pharm. Sci. 2002, 91, 2026-2038. [CrossRef]

43. Wang, Y.; Wei, D.; Dave, R.; Pfeffer, R.; Sauceau, M.; Letourneau, J.; Fages, J. Extraction and precipitation particles coating using supercritical $\mathrm{CO}_{2}$. Powder Technol. 2002, 127, 32-44. [CrossRef]

44. Meziani, M.J.; Pathak, P.; Hurezeanu, R.; Thies, M.C.; Enick, R.M.; Sun, Y.P. Supercritical-fluid processing technique for nanoscale polymer particles. Angew. Chem. Int. 2004, 3, 704-707. [CrossRef]

45. Pathak, P.; Meziani, M.J.; Desai, T.; Sun, Y.P. Nanosizing drug particles in supercritical fluid processing. J. Am. Chem. Soc. 2004, 126, 10842-10843. [CrossRef] [PubMed]

46. Reverchon, E.; Marco, I. Supercritical antisolvent micronization of Cefonicid: Thermodynamic interpretation of results. J. Supercrit. Fluids 2004, 31, 207-215. [CrossRef]

47. Rodier, E.; Lochard, G.; Sauceau, M.; Letourneau, J.; Freiss, B.; Fages, J. A three step supercritical process to improve the dissolution rate of Eflucimibe. Eur. J. Pharm. Sci 2005, 26, 184-193. [CrossRef]

48. Duarte, A.R.C.; Costa, M.S.; Simplicio, A.L.; Cardoso, M.M.; Duarte, C.M.M. Preparation of controlled release microspheres using supercritical fluid technology for delivery of anti-inflammatory drugs. Int. J. Pharm. 2006, 308, 168-174. [CrossRef]

49. Moura, C.; Casimiro, T.; Costa, E.; Aguiar-Ricardo, A. Optimization of supercritical $\mathrm{CO}_{2}$-assisted spray drying technology for the production of inhalable composite particles using quality-by-design principles. Powder Technol. 2019, 357, 387-397. [CrossRef]

50. Tabernero, A.; del Valle, E.M.M.; Galán, M.A. Supercritical fluids for pharmaceutical particle engineering: Methods, basic fundamentals and modelling. Chem. Eng. Process. Process. Intensif. 2012, 60, 9-25. [CrossRef]

51. Cabral, R.; Sousa, A.; Silva, A.; Paninho, A.; Temtem, M.; Costa, E.; Casimiro, T.; Aguiar-Ricardo, A. Design of experiments approach on the preparation of dry inhaler chitosan composite formulations by supercritical $\mathrm{CO}_{2}$-assisted spray-drying. J. Supercrit. Fluids 2016, 116, 26-35. [CrossRef]

52. Costa, C.; Nobre, B.; Matos, A.S.; Silva, A.S.; Casimiro, T.; Corvo, M.L.; Aguiar-Ricardo, A. Inhalable hydrophilic molecule-loaded liposomal dry powder formulations using supercritical $\mathrm{CO}_{2}$-assisted spray-drying. J. CO2 Util. 2021, 53, 101709. [CrossRef]

53. Long, B.; Walker, G.M.; Ryan, K.M.; Padrela, L. Controlling polymorphism of carbamazepine nanoparticles in a continuous supercritical- $\mathrm{CO}_{2}$-assisted spray drying process. Cryst. Growth Des. 2019, 19, 3755-3767. [CrossRef]

54. Adeoye, O.; Costa, C.; Casimiro, T.; Aguiar-Ricardo, A.; Cabral-Marques, H. Preparation of ibuprofen/hydroxypropyl- $\gamma-$ cyclodextrin inclusion complexes using supercritical $\mathrm{CO}_{2}$-assisted spray drying. J. Supercrit. Fluids 2018, 133, 479-485. [CrossRef]

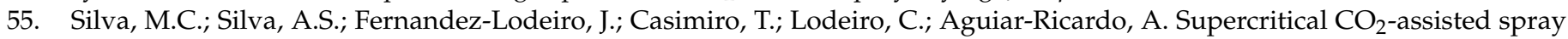
drying of strawberry-like gold-coated magnetite nanocomposites in chitosan powders for inhalation. Materials 2017, 10, 74. [CrossRef] [PubMed]

56. Tavares, M.; Cabral, R.P.; Costa, C.; Martins, P.; Fernandes, A.R.; Casimiro, T.; Aguiar-Ricardo, A. Development of PLGA dry powder microparticles by supercritical $\mathrm{CO}_{2}$-assisted spray-drying for potential vaccine delivery to the lungs. J. Supercrit. Fluids 2017, 128, 235-243. [CrossRef]

57. Franco, P.; De Marco, I. Nanoparticles and Nanocrystals by Supercritical $\mathrm{CO}_{2}$-Assisted Techniques for Pharmaceutical Applications: A Review. Appl. Sci. 2021, 11, 1476. [CrossRef]

58. Briggs, D.; Seah, M. (Eds.) Practical Surface Analysis, Auger and X-ray Photoelectron Spectroscopy, 2nd ed.; Wiley: Hoboken, NJ, USA, 1990; Volume 1, pp. 635-638.

59. Dahlberg, C.; Millqvist-Fureby, A.; Schuleit, M. Surface composition and contact angle relationships for differently prepared solid dispersions. Eur. J. Pharm. Biopharm. 2008, 70, 478-485. [CrossRef] [PubMed]

60. Kadav, A.; Vora, D. Stability indicating UPLC method for simultaneous determination of atorvastatin, fenofibrate and their degradation products in tablets. J. Pharm. Biomed. Anal. 2008, 48, 120-126. [CrossRef] [PubMed]

61. Cha, K.-H.; Cho, K.-J.; Kim, M.-S.; Kim, J.-S.; Park, H.J.; Park, J.; Cho, W.; Park, J.-S.; Hwang, S.-J. Enhancement of the dissolution rate and bioavailability of fenofibrate by a melt-adsorption method using supercritical carbon dioxide. Int. J. Nanomed. 2012, 7 , 5565.

62. Khan, K.A.; Rhodes, C.T. The concept of disolution efficiency. Pharm. Acta Helv. 1972, 47, 594-607. [PubMed]

63. Dollery, C. (Ed.) Therapeutic Drugs, 2nd ed.; Elsevier Health Sciences: Amsterdam, The Netherlands, 1999.

64. Patel, A.; Vavia, P. Preparation and in vivo evaluation of SMEDDS (Self-Microemulsifying Drug Delivery System) containing fenofibrate. AAPS J. 2007, 9, E344-E352. [CrossRef] [PubMed] 
65. Nutting, D.; Tso, P. Hypolipidemic effects of intravenous pluronic L-81 in fasted rats treated with Triton WR-1449: Possible inhibition of hepatic lipoprotein secretion. Horm. Metab. Res. 1989, 21, 113-115. [CrossRef] [PubMed]

66. Cho, E.; Cho, W.; Cha, K.-H.; Park, J.; Kim, M.-S.; Kim, J.-S.; Park, H.J.; Hwang, S.-J. Enhanced dissolution of megestrol acetate microcrystals prepared by antisolvent precipitation process using hydrophilic additives. Int. J. Pharm. 2010, 396, 91-98. [CrossRef]

67. Abuzar, S.M.; Hyun, S.-M.; Kim, J.-H.; Park, H.J.; Kim, M.-S.; Park, J.-S.; Hwang, S.-J. Enhancing the solubility and bioavailability of poorly water-soluble drugs using supercritical antisolvent (SAS) process. Int. J. Pharm. 2018, 538, 1-13. [CrossRef]

68. Kim, J.-S.; Kim, M.-S.; Park, H.J.; Jin, S.-J.; Lee, S.; Hwang, S.-J. Physicochemical properties and oral bioavailability of amorphous atorvastatin hemi-calcium using spray-drying and SAS process. Int. J. Pharm. 2008, 359, 211-219. [CrossRef]

69. Shetty, N.; Ahn, P.; Park, H.; Bhujbal, S.; Zemlyanov, D.; Cavallaro, A.; Mangal, S.; Li, J.; Zhou, Q.T. Improved physical stability and aerosolization of inhalable amorphous ciprofloxacin powder formulations by incorporating synergistic colistin. Mol. Pharm. 2018, 15, 4004-4020. [CrossRef]

70. Shetty, N.; Park, H.; Zemlyanov, D.; Mangal, S.; Bhujbal, S.; Zhou, Q.T. Influence of excipients on physical and aerosolization stability of spray dried high-dose powder formulations for inhalation. Int. J. Pharm. 2018, 544, 222-234. [CrossRef]

71. Corrigan, I. Retardation of polymeric carrier dissolution by dispersed drugs: Factors influencing the dissolution of solid dispersions containing polyethylene glycols. Drug. Dev. Ind. Pharm. 1986, 12, 1777-1793. [CrossRef]

72. Higuchi, W.; Mir, N.; Desai, S. Dissolution rates of polyphase mixtures. J. Pharm. Sci. 1965, 54, 1405-1410. [CrossRef]

73. Higuchi, W. Diffusional models useful in biopharmaceutics. J. Pharm. Sci. 1967, 54, 645. [CrossRef]

74. Faldt, P.; Bergenstahl; Carlsson, G. The surface coverage of fat on food powders analyzed by ESCA (Electron Spectroscopy for Chemical Analysis). Food Struct. 1993, 12, 225-234.

75. Kasim, N.; Whitehouse, M.; Ramachandran, C. Molecular properties of WHO essential drugs and provisional biopharmaceutical classification. Mol. Pharm. 2004, 1, 85-96. [CrossRef]

76. Hayakawa, T.; Shimoyama, K.; Sekiya, S.; Sekiguchi, M.; Inotsume, N. Pharmacoeconomomic evaluation of anti-hyperlipidemic agent fenofibrate. Yakugaku Zasshi 2002, 122, 1145-1151. [CrossRef] 